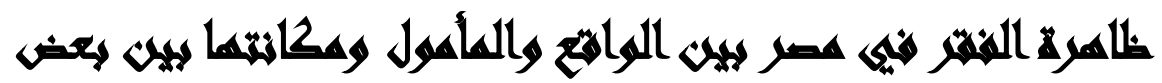 التول اللزاهية
}

[9]

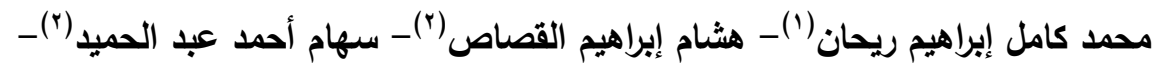

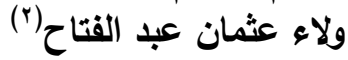

() قسم الاقتصاد الزراعي، كلية الزراعة، جامعة عين شمس بان باع قاعم العلوم الزراعية البيئية، معهد الدراسات والبحوث البيئية، جامعة عين شمس الافس

\section{المستحلص}

إن قضية الفقر خاصة في بلدان العالم الثالث تعد أحد أكبر التحديات التي تواجه العالم

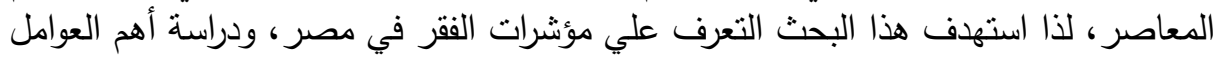

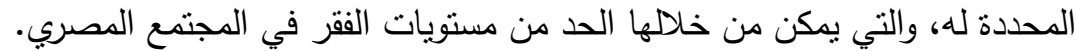

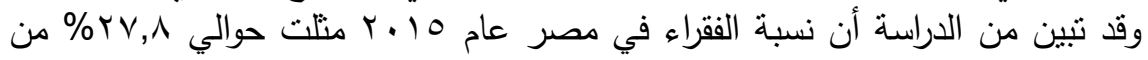

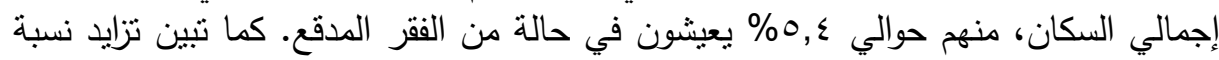

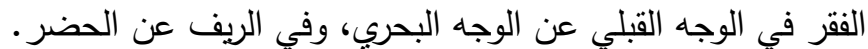

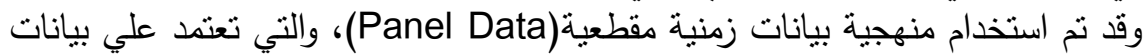

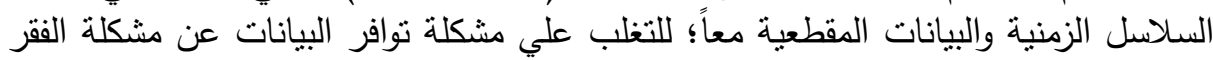

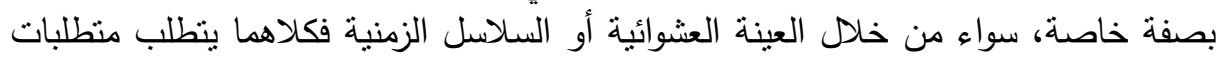

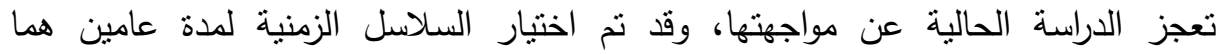

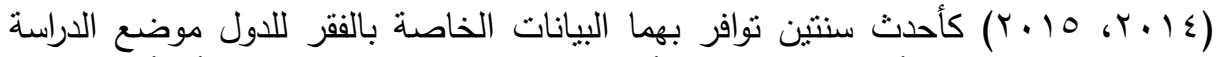

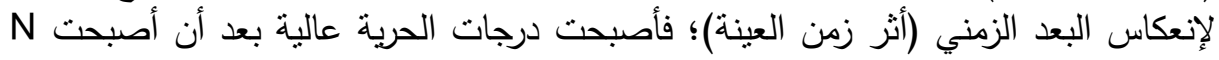

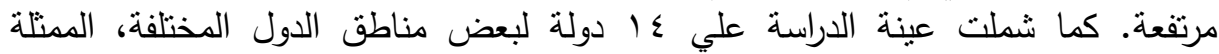

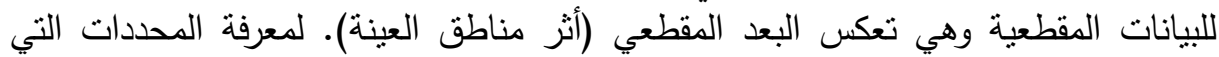

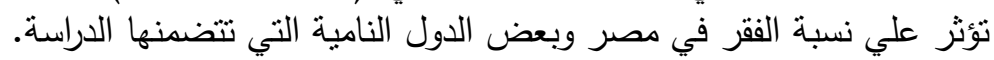

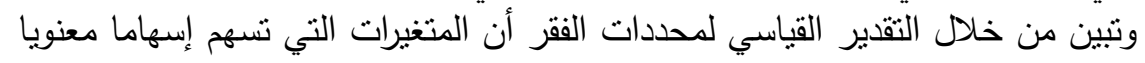

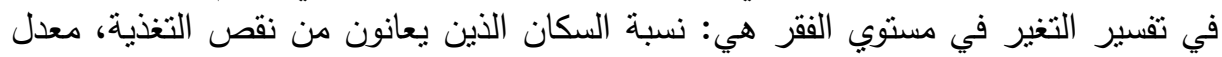

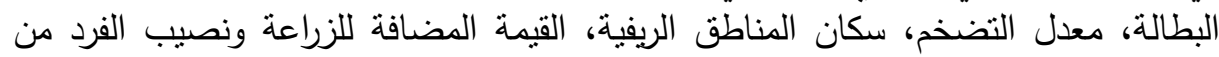

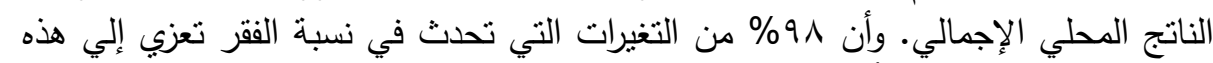

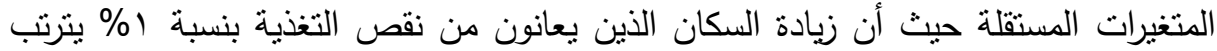

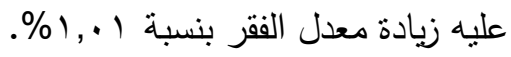

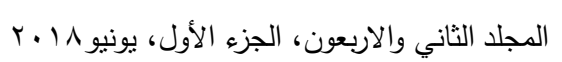




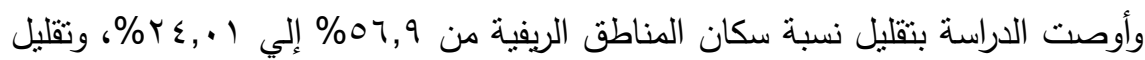

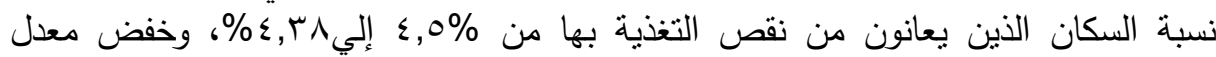

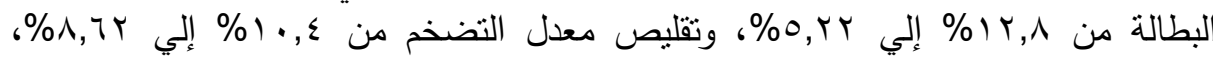

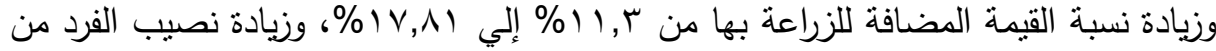

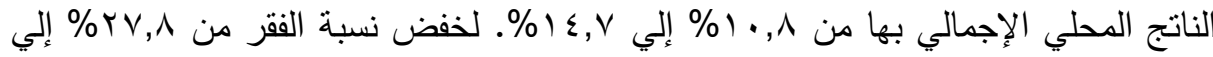

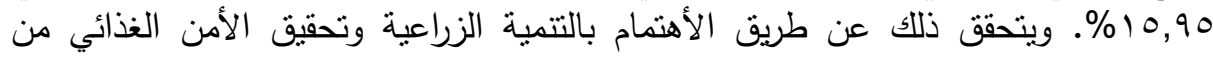

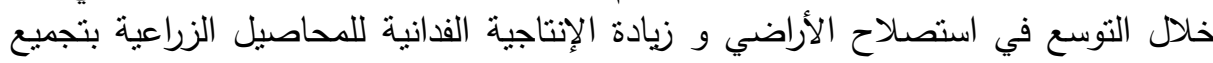

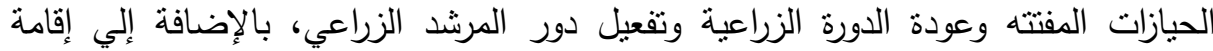

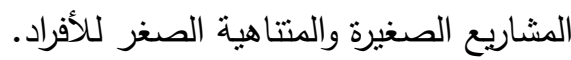
الكلمات الافتتاحية: الفقر ، الفقر القومي، الفقر المدقع، التتمية البشرية، محددات الفقر.

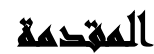

تمهيد: تعد قضية الفقر من أهم القضايا التي تتغلل صانعي القرار خاصة في الدول النامية.

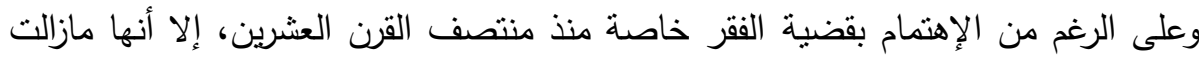
مستمرة إلى الآن، مما يعنى ضرورة وجود سياسات فاعلة لخفض الإنه الفقر نتبنى استراتيجيات بديلة

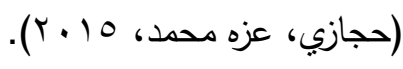
وفي السبعينيات كان يشار للفقر علي إنه إنخفاض في مستويات الدخل والإستهلاك ومن

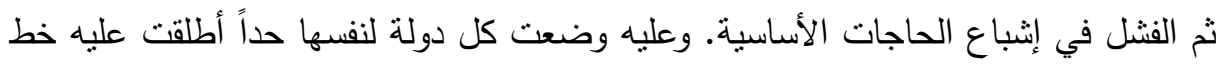

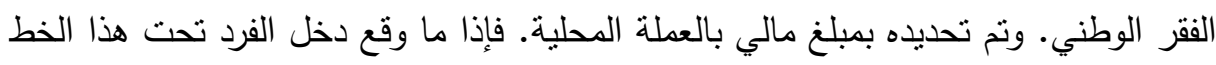

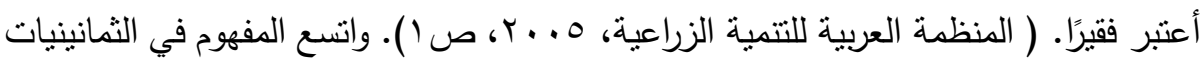

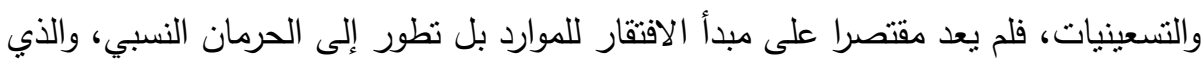

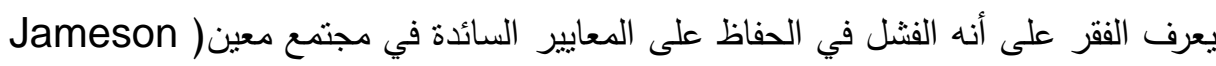
Boex; 2006 (Boe). وفي الآونة الأخيرة، تم تعميق هذا المفهوم ليشمل فكرة حرمان القدرات

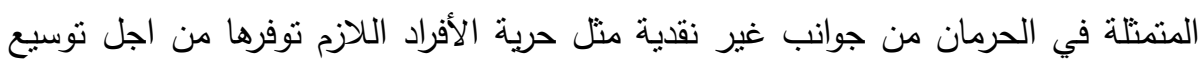
وتتمية القدرات البشرية وأي قدرات أخرى وذلك في إطار مدخل القدرة Capability

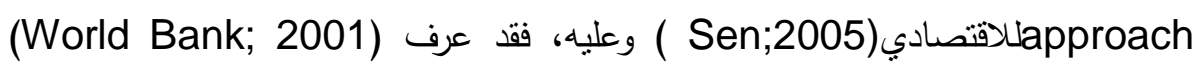
الفقر على أنه الحرمان الواضح من الرفاهية. وأنثار البنك الدولي إلى أن للفقر جوانب مختلفة 164

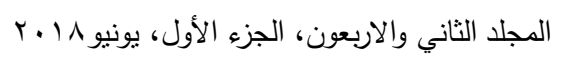


تتمثل في الدخل المنخفض، ومحدودية الحصول على التعليم والرعاية الصحية، وعدم وجود صوت أو سلطة، علاوة على الضعف والتعرض للمخاطر كما عرف الفقر النسبي علي إنه دخول بعض أسر المجتمع، وبعض أفراده تقل عن منوسط الدخل الذي يسود في هذا المجتمع، إذ يعدون فقراء بالنسبة إلى الآخرين، كما لا يمكنه دخلهم من الحصول على علي الاحتياجات

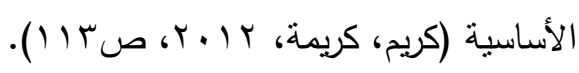

فالفقر المطلق: يعنى عدم قدرة الفرد أو الأسرة على توفير احتياجاتهم الأساسية الغذائية وغير

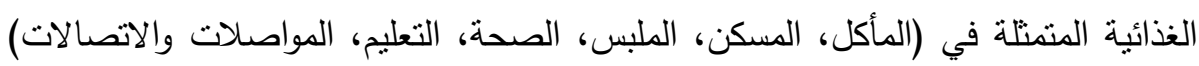

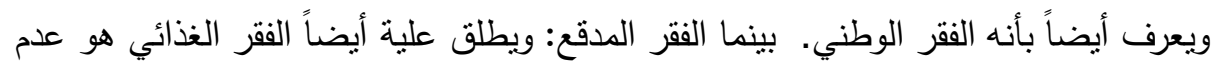

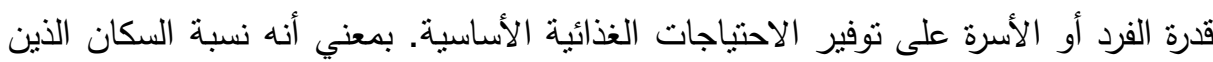

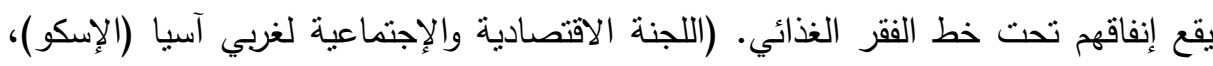

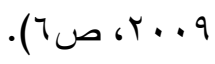

ويعرف خط الفقر القومي بأنه: تكلفة الحصول علي السلع والخدمات الأساسية للفرد او الأسرة

$$
\text { ويتكون من مكونان هما مكون غذائي وغير غذائي. }
$$

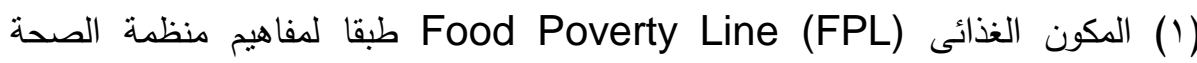
العالمية وصندوق الغذاء العالمى هو نكلفة سلة سلع غذائية تتسجم مع السلوك الإستهلاكى لهى

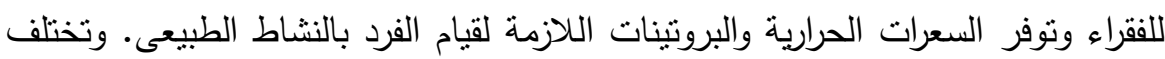
تكلفة السلع الغذائية باختلاف المناطق الجغرافية ويمنل خط الفقر الغذائى - إلى حد

$$
\text { كبير - كلفة البقاء على قبد الحياة. }
$$

(r) المكون غير الغذائى : يتم تقديره بعد تحديد خط الفقر الغذائى وهو نسبة من الإنفاق

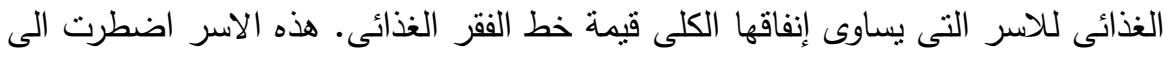

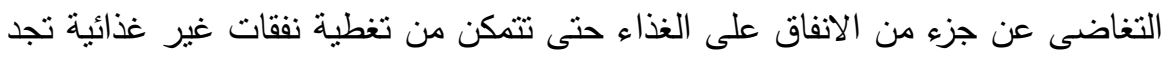

$$
\text { نفسها غير قادرة عن الاستغناء عنها. }
$$

خط الفقر القومى = المكون الغذائى + المكون غير الغذائى(الخولانى، محمد محمد،

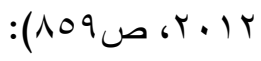

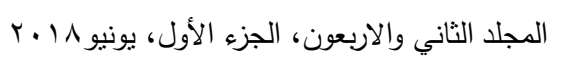


ويمكن قياس الفقر عن طريق التعبير عن عدد الفقراء كنسبة من السكان أو عن طريق قياس مستوى المعيشة معبرا عنها بدخل العائلة أو متوسط نفقات الفرد. ومعامل جيني الدال

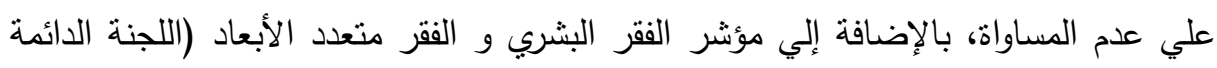

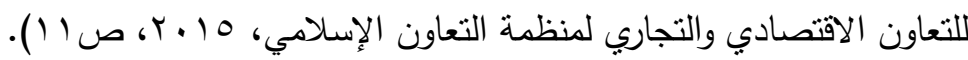
وينتشر الفقر بشكل أوسع في المناطق الريفية، وحسب الإتجاهات الحالية، لن تقل نسبة الإسبة

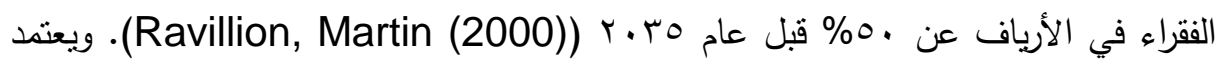
معظم السكان الريفيين علي الزراعة، ومما لا شك فيه أن الزراعة محورأ رئيسياً في أي عملية

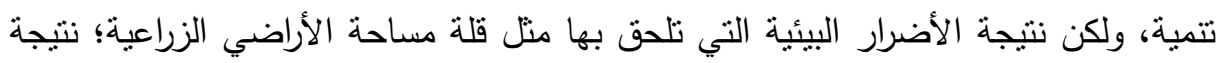

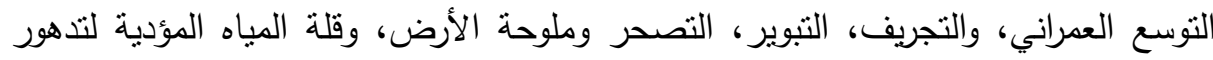
الإنتاجية، والتزايد في عدد السكان وزيادة الإستهلاك تكون عائق أمام التتمية، (الطحلاوي،

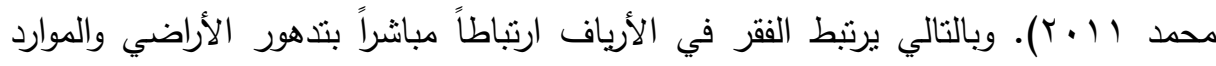
الطبيعية؛ فالتذهور يتسبب في الفقر، وفي حالات كثيرة، يجعل الفقر من إصلاح الموارد

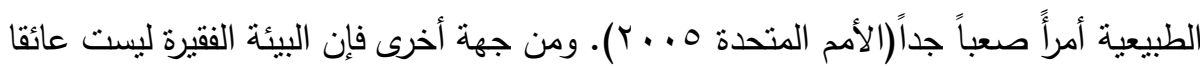
حتميا أمام التتمية، ما دام هناك رأسمال بشري مؤهل وكاف لتوظيف القدرات البشرية في عملية التتمية، فالفقر يرتبط ببيئة غير صحية فقيرة من الرأسمال البشري والنقافي، أكثر مما هي ببيئة محدودة الموارد المادية (2002) (2hyamsundar, Priya). ويلاحظ أن التمكين القانوني للأشخاص والجماعات الفقيرة، ومنحهم حقوقًا تتعلق بالأراضي و تكافؤ فرص حصولهم

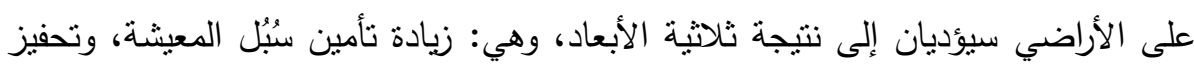

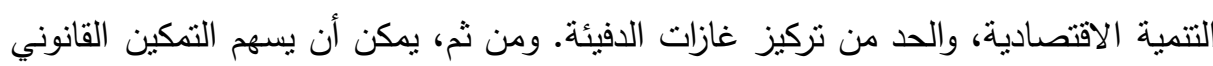
للفقراء في الحد من الفقر على نحو مستدام (الأمم المتحدة، 9 . . ؟ ب). ومما سبق يتبين أن الفقر بصفة عامة من أكبر التحديات التي تواجه البشرية، وأسبابها

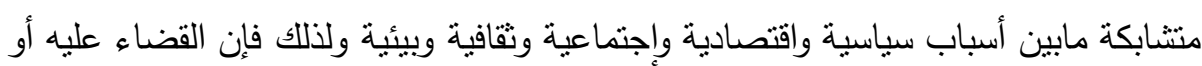
الحد منه ضرورة اقتصادية وسياسية؛ سوف يؤدي إلي وقف التدهور البيئي والاستنزاف لموارد الأرض والمياه، وبالتالي الوصول للتتمية المستدامة، فضلًا عن أنها ضرورة إنسانية أولًا. 


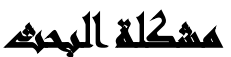

يعتبر الفقر من أبرز الظواهر الإجتماعية والاقتصادية المعدة، والتي تتسبب فيها عدة عوامل، فهي ظاهرة منتشرة في جميع أنحاء العالم ولا تقتصر على جزء جغرافي العرافي معين،

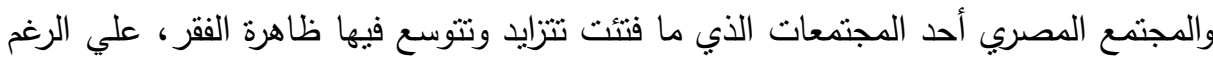

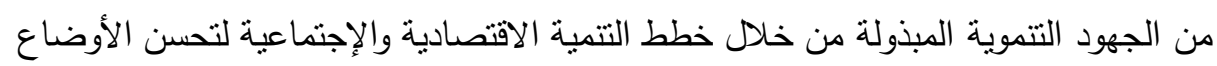
الاقتصادية والإجتماعية علي مر الزمن علي المستوي المحلي والعالمي لتقليل مشكلة الفقر؛

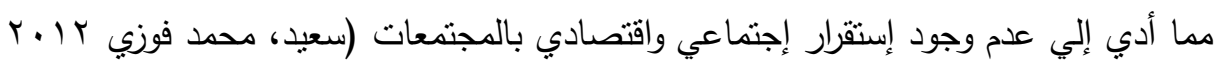

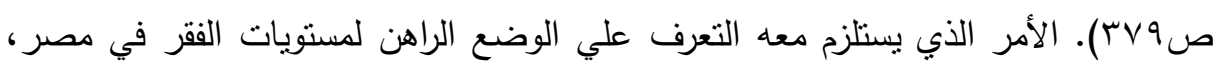

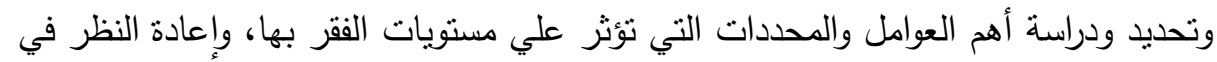

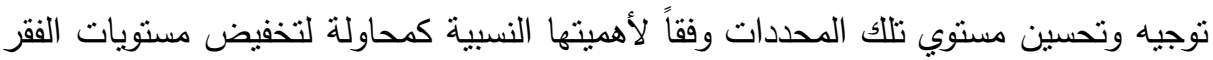
في مصر تبعاً للمستوي القياسي المفترض من قبل البحث.

\section{اهساهيت السراسما}

يهدف البحث إلي تحليل الوضع الراهن لمستويات الفقر في مصر، والتقدير الإحصائي

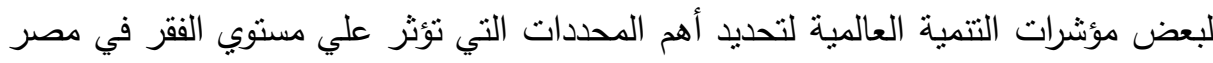
القائم حالياً وبعض الدول النامية؛ وإمكانيات خفض نسبة الفقر في مصر إلي أفضل مستوي ممكن. وتحقيق الوضع المأمول له.

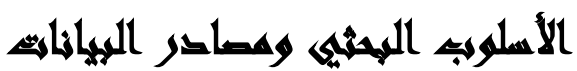

اعتمد البحث علي إستخدام أساليب التحليل الإحصائي الوصفي والكمي للتعرف علي

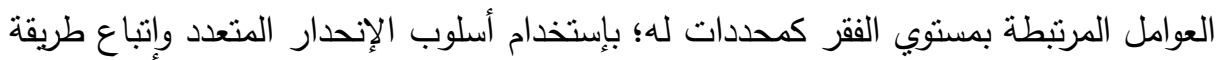
المربعات الصغري العادية "OLS" في التقدير لبيانات زمنية مقطعية. كما اعتمد البحث علي لئل البيانات الثانوية المنشورة من قبل بعض الأجهزة المحلية كالجهاز المركزي للتعبئة العامة والإحصاء واستخدام بيانات بحث الإنفاق والإستهلاك والدخل لأعداد متفرقة خلال الفترة من لنه

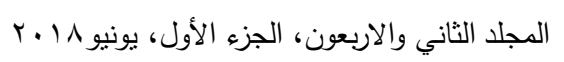


.

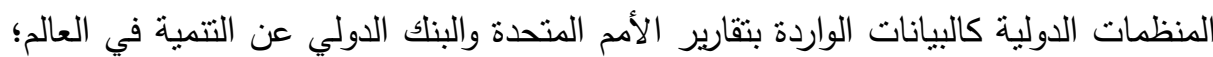
وترتيباً علي ذلك نم استخدام منهجية بيانات زمنية مقطعية(Panel Data)، والتي تعتمد

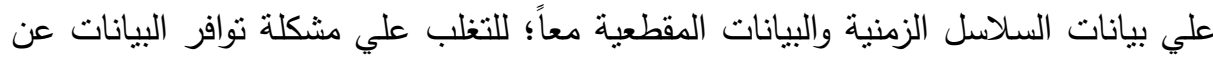
مشكلة الفقر بصفة خاصة، سواء من خلال العينة العشوائية أو السلاسل الزمنية فكلاهما ينطلب منطلبات تعجز الدراسة الحالية عن مواجهنها، وقد نم اختيار السلاسل الزمنية لمدة

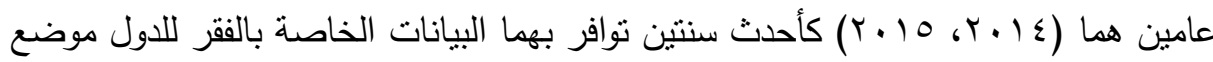

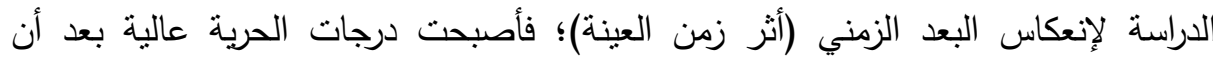
أصبحت N مرتفعة. كما شملت عينة الدراسة علي ؟ ا دولة لبعض مناطق الدول المختلفة، الممثلة للبيانات المقطعية وهي تعكس البعد المقطعي (أثز مناطق العينة). وذللك لتحديد

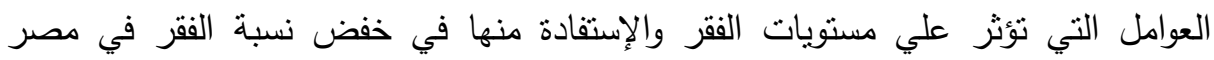
وتحقيق الوضع المأمول في انخفاضها.

\section{المتحأيج وهنالهمتهما}

أولأً: الوضع الراهن للفقر في مصر

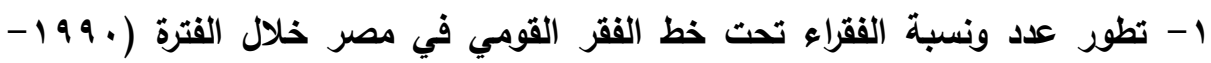

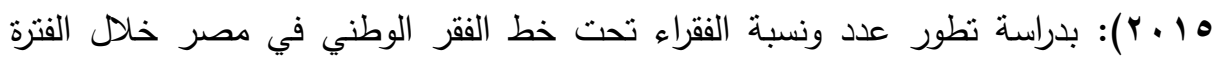

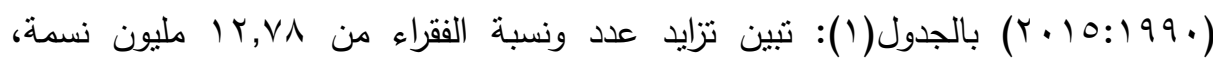

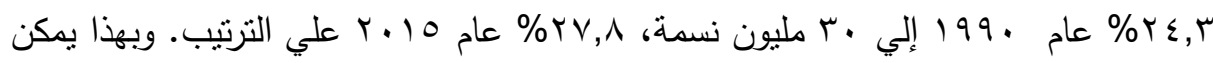

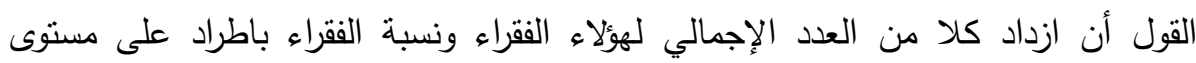

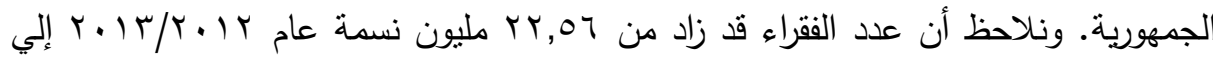

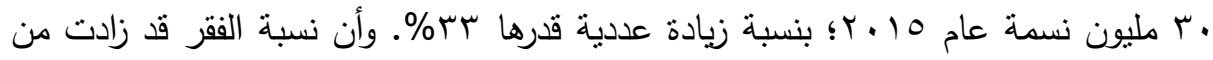

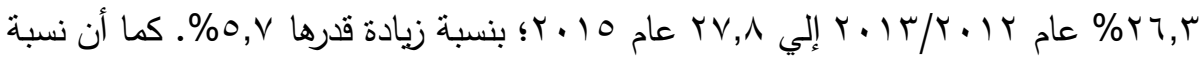
الفقراء عام 2015 هى الأعلى منذ عام 1990. وهذا ما يدعو للقلق من تمادي زيادة نسبة

$$
\text { المجلد الثاني والاربعون، الجزء الأول، يونيو \\· }
$$


وعدد الفقراء في مصر ؛ لذلك بلزم البدأ فوراً في التتسيق بين كافة مؤسسات الدولة من أجل القضاء علي الفقر.

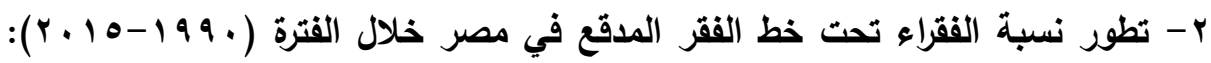

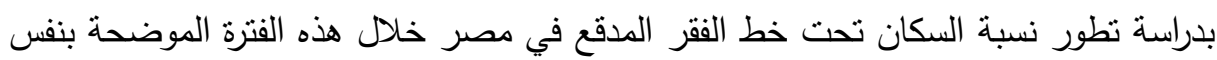
الجدول تبين أن هنالك تحسن وانخفاض ملحوظ في نسبة الفقراء وفقاً لمقياس الفقر المدقع بالرغم من الإرتفاع المتزايد في نسبة الفقراء حسب مقياس الفقر الوطني، فقي

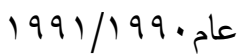

جدول رقم(1) : نطور عدد ونسبة الفقراء تحت خط الفقر المطلق، والمدقع في مصر خلال

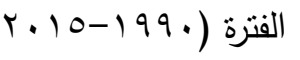

\begin{tabular}{|c|c|c|c|}
\hline نسبة الفقر & عالمليون الفقراء & نسبة السكان تحت خط الفقر & 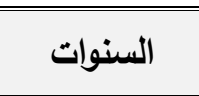 \\
\hline 8.9 & 12.78 & 24.3 & $1991 / 1990$ \\
\hline 2.9 & 10.65 & 16.7 & $2000 / 1999$ \\
\hline 3.6 & 14.24 & 19.6 & $2005 / 2004$ \\
\hline 6.1 & 16.3 & 21.6 & $2009 / 2008$ \\
\hline 4.8 & 19.61 & 25.2 & $2011 / 2010$ \\
\hline 4.4 & 22.56 & 26.3 & $2013 / 2012$ \\
\hline 5.4 & 30 & 27.8 & 2015 \\
\hline
\end{tabular}

المصدر: الجهاز المركزي للتعبئة العامة والاحصاء، بحث الدخل والإنفاق، أعداد متفرقة.

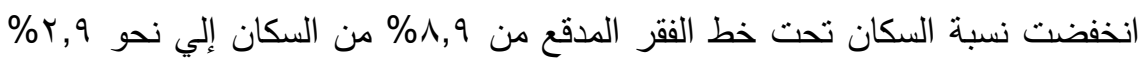

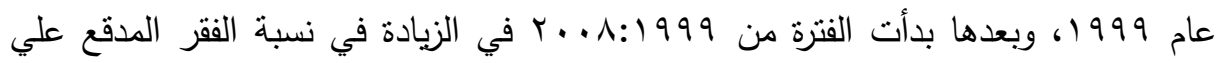

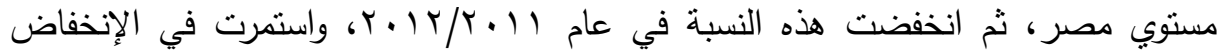

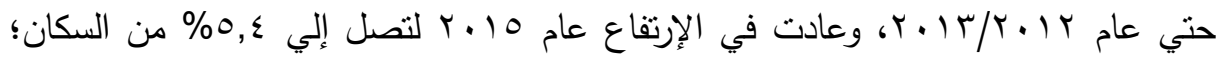
وقد برجع هذا الارتفاع إلي ارتفاع أسعار المواد الغذائية وغلاء المعيشة في مصر .

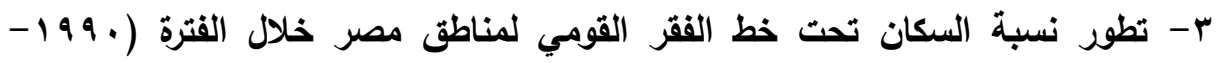
0 • ب): بدراسة نطور نسبة السكان تحت خط الفقر القومي (نسبة الفقراء) في المناطق المختلفة لمصر خلال هذه الفترة تبين؛ تذبذب نسبة السكان تحت خط الفقر القومي في كل

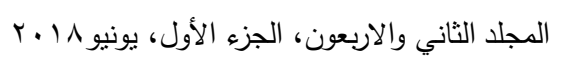


المناطق علي مستوي الجمهورية، فاتضح أن المحافظات الحضرية أقل مناطق الجمهورية فقراً تليها، منطقة حضر وجه بحري ثم ريف وجه بحري، وعلي النقيض فكانت منطقة الوجه القبلي

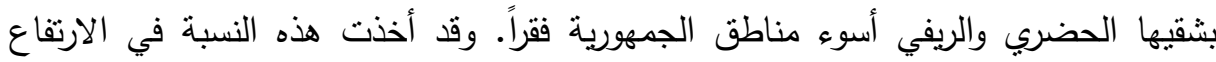

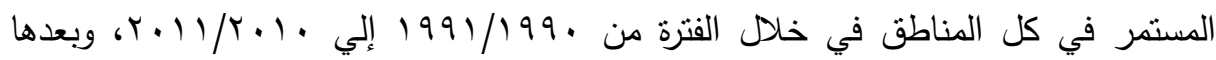
بدأت هذه النسبة في الإنخفاض علي مستوي أقاليم مصر، فيما عدا منطقة المحافظات

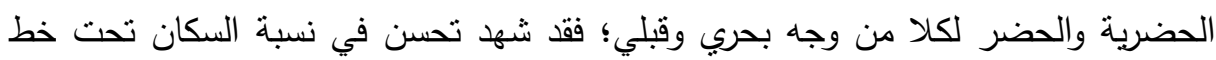

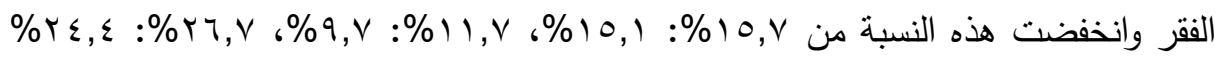
علي الترتيب. في حين لم يحدث أي إنخفاض في هذه النسبة علي مستوي الريف المصري بل تزايدت ووقع المزيد من الريفيين في براثن الفقر • ومن هنا يمكن القول أن نسبة السكان تحت خط الفقر القومي آخذ في الانكماش علي مستوي حضر مصر، ولكن ولكنه مازال واسع الانتشار

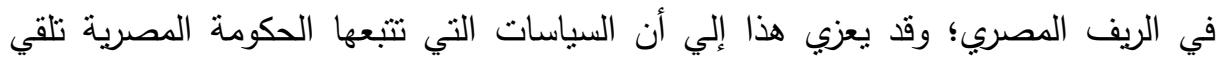

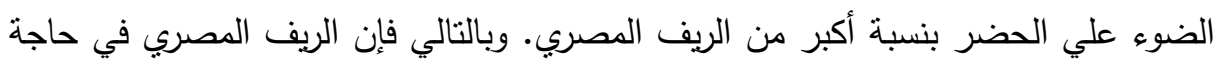
ملحة وماسة إلي توجيه الإهتمام الثديد به؛ لتقليل وتحسين نسبة السكان الواقعين تحت خط التهبه الفقر القومي ومساعدتهم علي الخروج من براثن الفقر . ؛ - مستوي الفقر علي مستوي محافظات الجمهورية: وفقاً لتقرير الجهاز المركزى للتعبئة

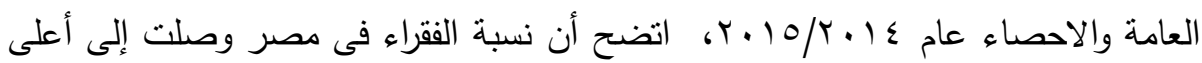

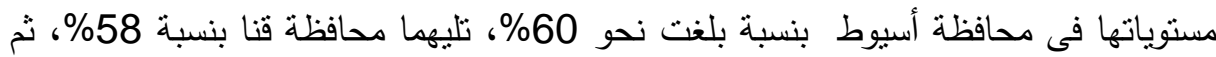

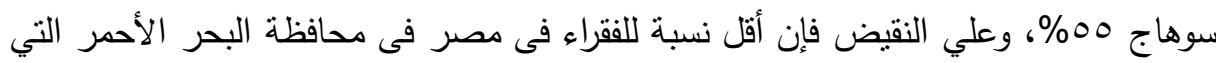

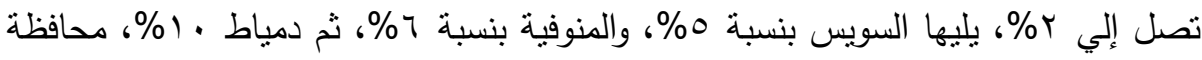

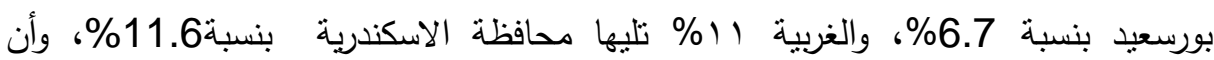
18\% من سكان القاهرة من الفقراء.

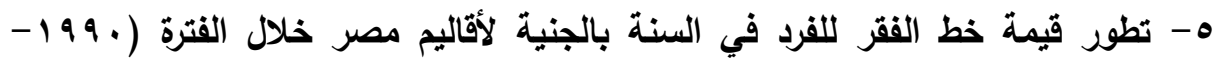
0 ا ب): نرجع أهمية خط الفقر إلى سهولته فى تحديد الحاجات الأساسية اللازمة لمعيشة 
الإنسان من ملبس، مأكل، مسكن، رعاية صحية، تعليم و وسائل مواصلات، ويعرف بإنه

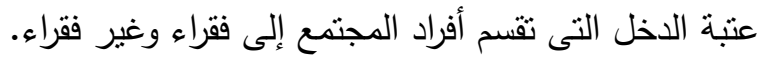
وبدراسة قيمة خطوط الفقر للفرد بمصر خلال الفترة المذكورة بالجدول (Y) أتضح أن:

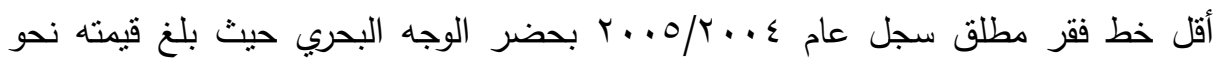

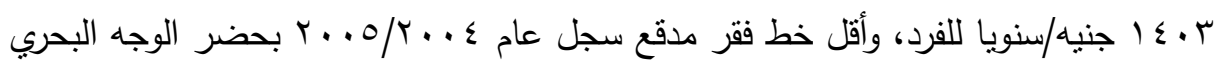
أيضاً حيث بلغ قيمته نحو

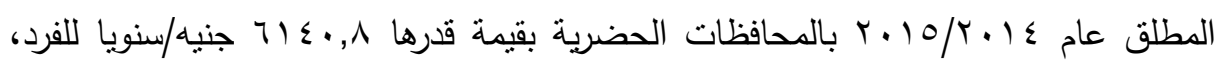

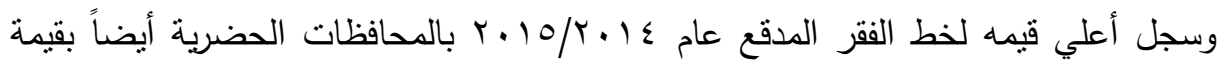

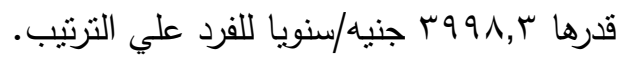

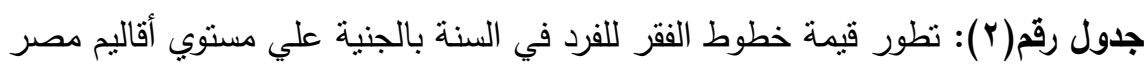

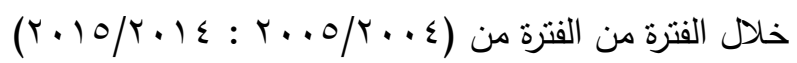

\begin{tabular}{|c|c|c|c|c|c|c|c|}
\hline الجمهورية & القيفله & القبّل & البحجه & الوضه & حضرية & السنواتت & خط الفقر \\
\hline $1 \leqslant Y T$ & $1 \varepsilon \cdot \Lambda$ & $1 \leqslant 17$ & $1 \leqslant r q$ & $1 \varepsilon . r$ & $1 \leqslant 04$ & 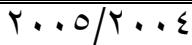 & \multirow{4}{*}{ خط الفقر } \\
\hline$r \cdot v^{\prime}$ & $r .19$ & rI $\leqslant \varepsilon$ & r991 & r. ro & TM & $r .11 / r_{0} .1$ & \\
\hline rqY. & rVT. & r971 & YAO\& & rATo & $\varepsilon \pi \backslash \Lambda$ & $T .1 T / R .1 T$ & \\
\hline OVAA & $079 \varepsilon$ & ONYT & $07 V 0$ & $07 \pi 1$ & $71 \leqslant 1$ & K.10/K.1E & \\
\hline 990 & 990 & $9 \wedge \varepsilon$ & 919 & $9 \vee 0$ & $1 . Y 0$ & $r_{\ldots .0 / r \ldots \varepsilon}$ & \multirow{4}{*}{ خط الفقر } \\
\hline$r .71$ & $r \cdot r q$ & $r \cdot T)$ & $Y \cdot \Sigma T$ & $197 \mathrm{~V}$ & Y)19 & $r .11 / r \cdot 1$. & \\
\hline rov. & $r \leqslant q 4$ & YOTY & Y074 & $r \leqslant \wedge$. & rVOI & $r .1 T / K \cdot I r$ & \\
\hline ए人Tा & rAY. & rVqY & rAV. & $r V \leqslant \Lambda$ & $r 991$ & $\left.r \cdot 10 / r^{\prime}\right) \varepsilon$ & \\
\hline
\end{tabular}

المصدر: الجهاز المركزي للتعبئة العامة والاحصاء، بحث الدخل والإنفاق، أعداد متفرقة.

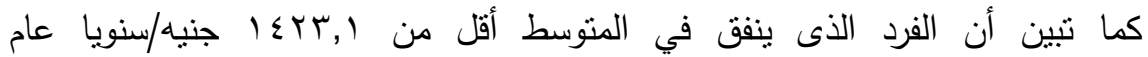

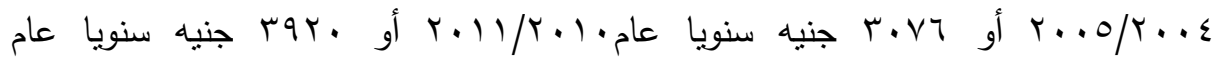

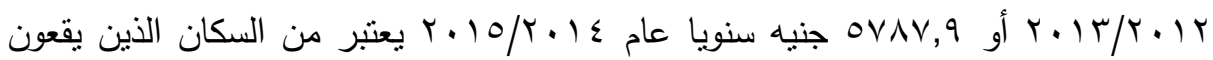

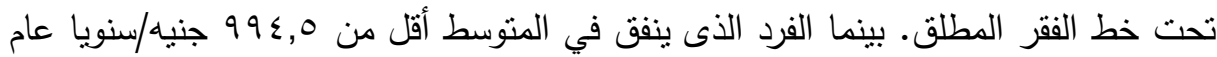

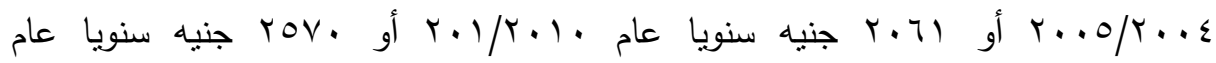




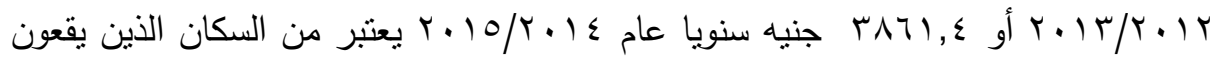

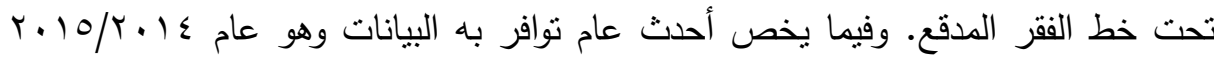

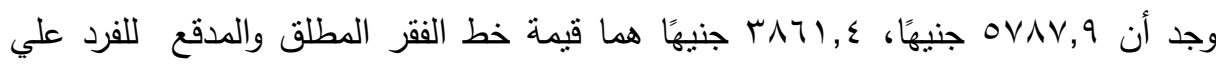

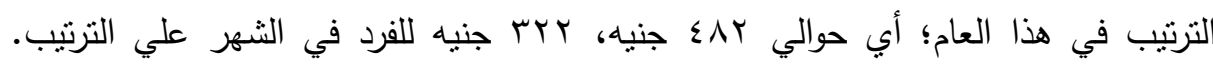

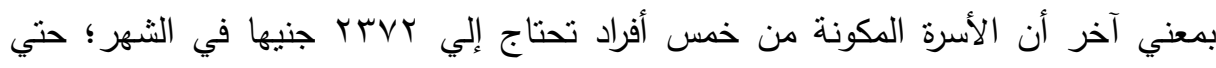
تستطيع الوفاء بإحتياجاتها الأساسية. وقد بلغ خط الفقر العالمي وفقاً لآخر تقارير البنك الدولي

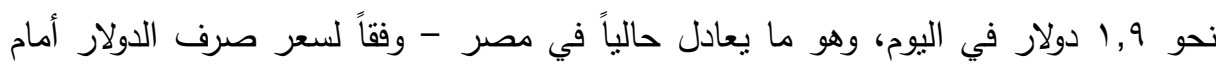

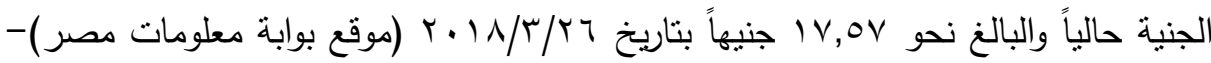

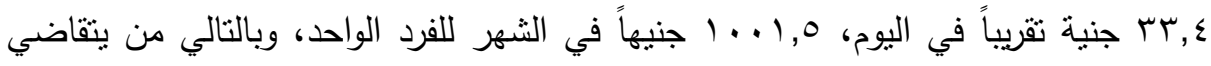
أقل من ذلك يومياً فيعتبر تحت خط الفقر.

צ- الاتجاهات الزمنية العامة للفقر في مصر خلال فترة الدراسة: وبدراسة معادلة الاتجاه

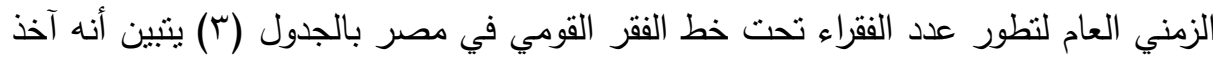

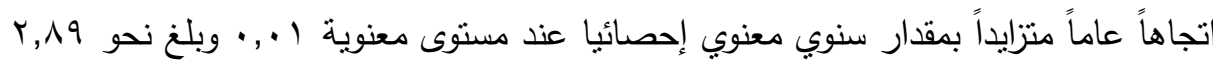

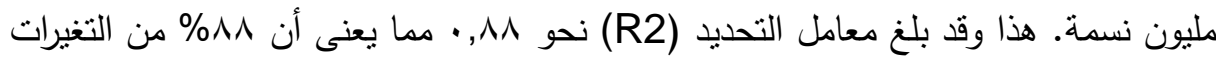
في عدد الفقراء تحت خط الفقر القومي ترجع للعوامل التي يعكس أثرها متغير الزمن، هذا وقد أند

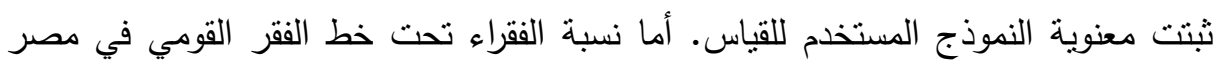

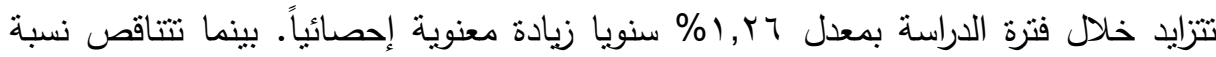

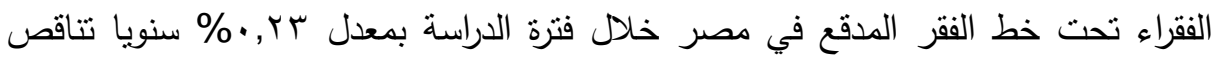
غير معنوي إحصائياً. 
جدول(ץ): الاتجاهات الزمنية العامة لعدد ونسبة الفقراء تحت خط الفقر المطلق، والمدقع في

\begin{tabular}{|c|c|c|c|}
\hline \multicolumn{4}{|c|}{ 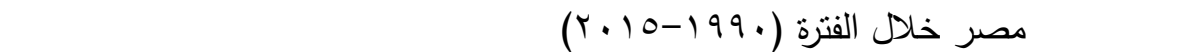 } \\
\hline المعادلة & $\overline{\mathbf{R}^{2}}$ & $\mathbf{F}$ & البيان - lل البيان \\
\hline $\begin{array}{l}\mathrm{Y}_{\mathrm{i}}=6.47+2.89 \mathrm{X}_{\mathrm{i}} \\
(3.02)^{* * *}(6.02)^{* * *}\end{array}$ & $\cdot, \wedge \wedge$ & r ז, r & عدد الفقراء تحت خط الفقر القومي \\
\hline $\begin{array}{l}Y_{1 \mathrm{i}}=18.03+1.26 \mathrm{X}_{\mathrm{i}} \\
(6.81)^{* * *}(2.13)^{*}\end{array}$ & $\cdot, \leqslant \wedge$ & $\varepsilon, 0$ & نسبة الفقراء تحت خط الفقر \\
\hline $\begin{array}{l}\mathrm{Y}_{2 i}=6.06-0.23 \mathrm{X}_{\mathrm{i}} \\
(3.44)^{* *} \quad(0.57-)\end{array}$ & 0.06 & 0.3 & نسبة الفقراء تحت خط الفقر المدقع \\
\hline
\end{tabular}

حيث:

الفقراء تحت خط الفقر القومي ونسبة الفقراء تحت خط الفقر المدقع علي الترتيب خلال الفترة i

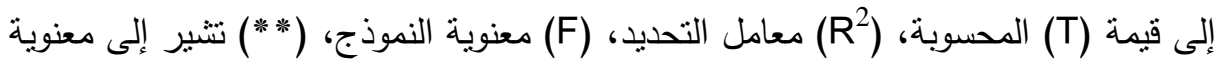
معاملات الإنحدار عند مسنوى معنوية (0.01)، (") نتشير إلى المعنوية عند مسنوى معنوية

المصدر: حسبت من بيانات الجدول رقم (1) بالدراسة. ثانياً: محددات الفقر في مصر ويعض الاول المختارة: يعاني البشر من الفقر

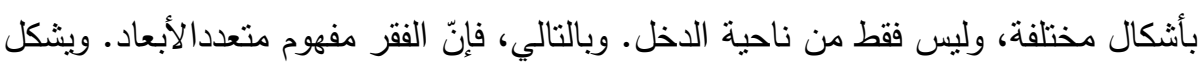

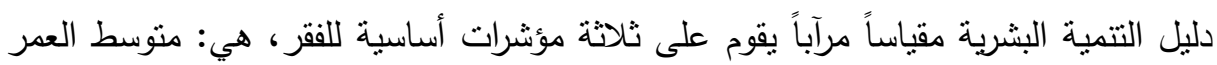
المتوقع والتحصيل العلمي والدخل. ويوفر هذا الدليل مقياساً أكثر تكاملاً وشمولية للفقر مقارنة

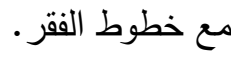
فالتنمية البشرية: هي عملية توسيع خيارات الإنسان، هي تتمية الإنسان ببناء الإمكانات

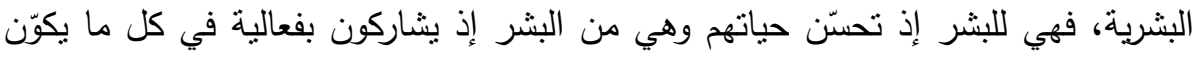

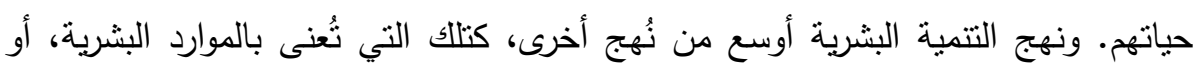

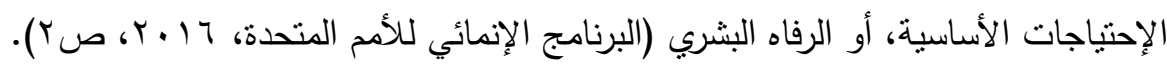




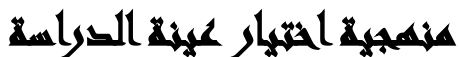

تعد مصر أحد الدول منوسطة التتمية البشرية MDCs حيث بلغ نرتبها ضدن الدول وفقاً لدليل التتمية البشرية HDI نحو 111 من إجمالي 111 دولة. وبما أن الهدف من هذا الجزء لهن

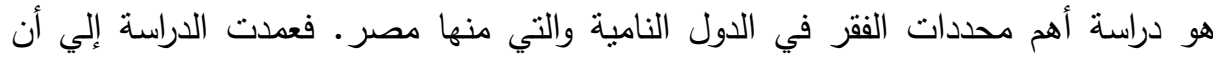
تكون الدول المختارة بعينة الدراسة كلها تقع تحت المجموعة الثالثة؛ وهي مجموعة الدول ذات التتمية البشرية المتوسطة، فيما عدا ثلاث دول نم اختيارهما من المجموعة السابقه لها ليكونوا كأساس للمقارنة. مع مراعاة أن تكون قريبة من الظروف والمستوي الخاص بالدول النامية المختارة بعينة الدراسة لضمان التجانس بين مفرداتها، وكانت هذه الدول ماليزيا، البرازيل وتونس ويحتلوا الرتبة رقم 99، 9 9، و في الدول ذات التتمية البشرية المرتفعة علي الترتيب. كما عمدت الدراسة بأن تمنل الدول المختارة لعينة الدراسة من مناطق مختلفة من العالم، تزداد وتتتاقص فيها دليل التتمية البشرية عن منيله في مصر كالتالي: 1- منطقة شرق وجنوب آسيا: وتمنلها دول ماليزيا، الفلبين، اندونيسيا، الهند، بنجلاديش وباكستان.

r- منطقة الثرق الأوسط وشمال أفريقيا: وتمنلها دول تونس، مصر، العراق و المغرب. r- منطقة أفريقيا جنوب الصحراء: وتمثلها دول غانا، زامبيا، كينيا، جابون و الكونغو.

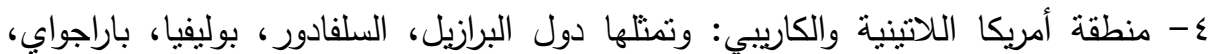

$$
\text { هنداروس وغيانا. }
$$

وبعبارة أخري فإن اختيار دول عينة الدراسة راعت تمثيل الدول إلي حد بعيد من حيث

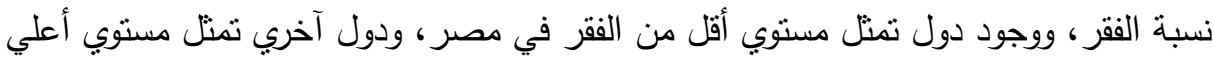
للفقر مقارنة بمصر • ذلك بالإضافة إلي مدي توافر الإحصاءات عن كل دولة علي حدا كما

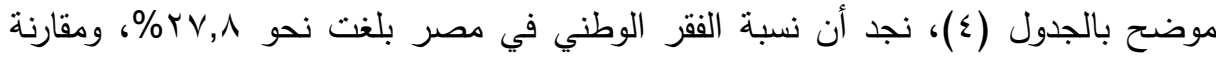
بباقي دول المنطقة نجد أن نونس والمغرب تحظي بنسبة فقر أقل من مصر حيث بلغت بلن نسبة

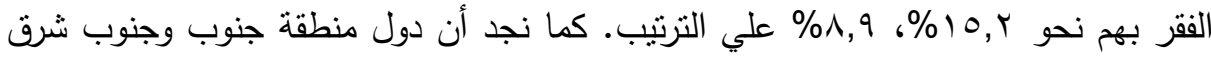
آسيا بها نسبة فقر أقل من مصر بإستثناءباكستان وبنجلاديش، وعلي النقيض فإن دول منطقة 
أمريكا اللاتينية والكاريبي تفوق مصر من حيث نسبة الفقر فيما عدا البرازيل وباراجواي. وسوف نتتاول ثأثثر الدحددات سالفة الذكر علي نسبة الفقر بالعينة موضع الدراسة. ومن بين الأسباب التي باعدت بين دخول بعض الدول في عينة الدراسة؛ تلك المشاكل

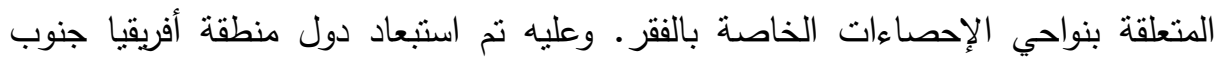
الصحراء، ودولة العراق بمنطقة الثرق الأوسط وشمال افريقيا، ودولة غيانا بمنطقة أمريكا

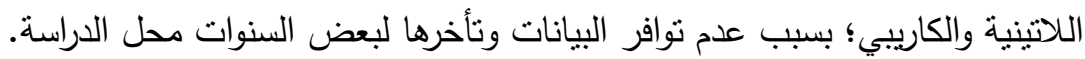

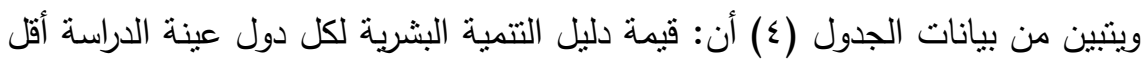
من 799, • وأعلي من •00, • أي إنها تقع تحت مجموعة الدول ذات التمبية البشرية المتوسطة، ماعدا ثلاث دول وهما ماليزيا، البرازيل وتونس حيث بلغت فئ قيمت الدليل لهم نحو

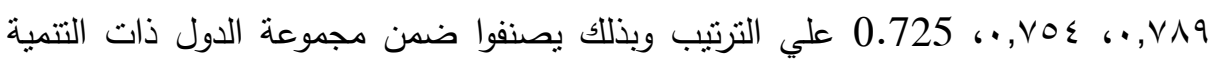
البشرية المرتقعة. وقد تراجعت مصر r مرات في الترتيب طبقاً لنرتيب دليل النتمية البشرية

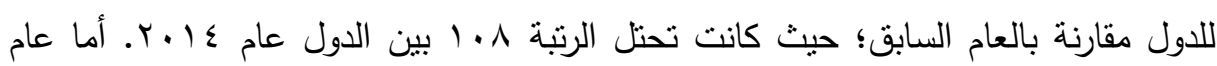

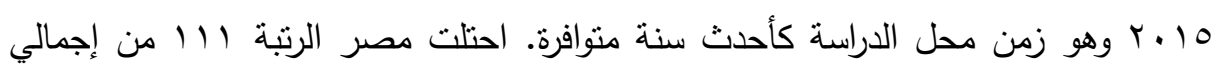

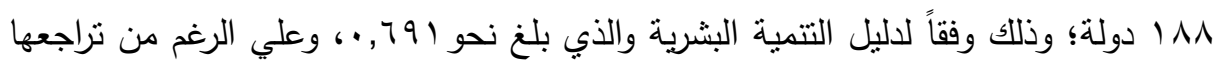

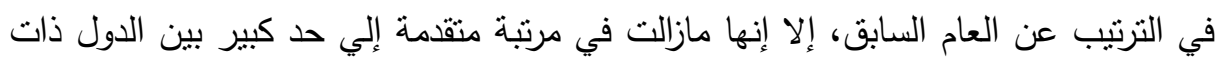

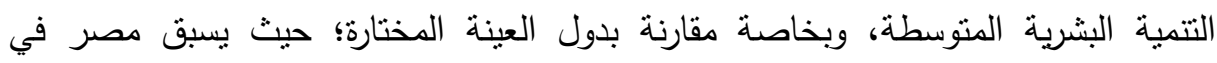
الترتيب دولة باراجواي فقط من إجمالي الدول المختارة للعينة. أما باقي دول العينه فيأتي

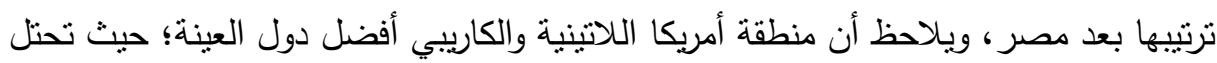
دول هذه المنطقة رتب متقدمة وفقاً لدليل التتمية البشرية، وقيمة الفقر البشري متعدد الأبعاد، وتليها منطقة الثرق الأوسط وشمال أفريقيا التي تقع بها مصر ـ وتأتي في المرنبة الأخيرة دول

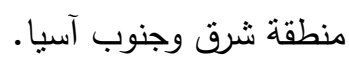


جدول رقم(؛ ): نسبة السكان تحت خط الفقر القومي وقيمة دليلي التتمية البشرية والفقر متعدد

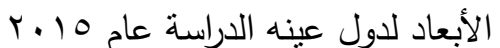

\begin{tabular}{|c|c|c|c|c|c|c|}
\hline \multicolumn{2}{|c|}{ دليل الفقر المتعدد الأبعاد } & تصت السكانة & \multicolumn{2}{|c|}{ دليل التنمية البشرية } & الدولة & المنطقة \\
\hline - & - & 0.6 & 59 & 0.789 & ماليزيا & \multirow{6}{*}{ وجنوب شرق } \\
\hline 2013 & 0.033 & 21.6 & 116 & 0.682 & الفلبين & \\
\hline 2012 & 0.024 & 11.2 & 113 & 0.689 & اندونيسيا & \\
\hline $2005 / 2006$ & 0.282 & 21.9 & 131 & 0.624 & الهند & \\
\hline 2014 & 0.188 & 24.3 & 139 & 0.579 & بنجلاديش & \\
\hline $2013 / 2012$ & 0.237 & 29.5 & 147 & 0.55 & باكستان & \\
\hline $2012 / 2011$ & 0.006 & 15.2 & 97 & 0.725 & تونس & \multirow{3}{*}{ وشمال الفريقيا } \\
\hline 2014 & 0.016 & 27.8 & 111 & 0.691 & مصر & \\
\hline 2011 & 0.069 & 8.9 & 123 & 0.647 & المغرب & \\
\hline 2014 & 0.01 & 8.7 & 79 & 0.754 & البرازيل & \multirow{5}{*}{ وأمريكا اللاتينية } \\
\hline- & - & 34.9 & 117 & 0.680 & السلفادور & \\
\hline 2008 & 0.097 & 38.6 & 118 & 0.674 & بوليفيا & \\
\hline- & - & 26.6 & 110 & 0.693 & باراجواي & \\
\hline $2012 / 2011$ & 0.098 & 63.8 & 130 & 0.625 & هنداروس & \\
\hline
\end{tabular}

المصدر: برنامج الأمم المتحدة، تقرير التتمية البشرية، 17 ـ ب. وموقع البنك الدولي.

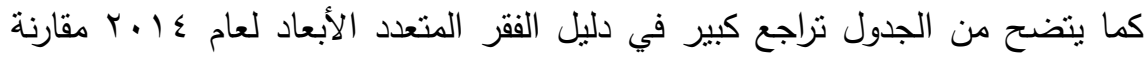

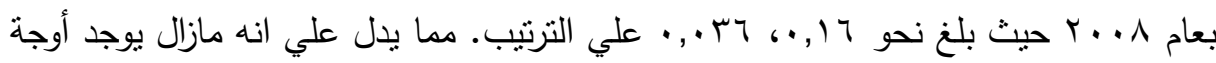

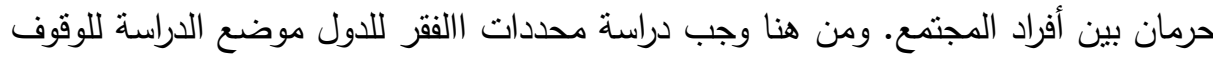
علي أهم العوامل التي تؤثر في الفقر ومحاولة تتمياتها لتقليل الفقر بين أفراد المجتمع. يتأثز الفقر كغيره من الظواهر الإجتماعية بالعديد من المتغيرات، ومن ثم قامت الدئ الدراسة

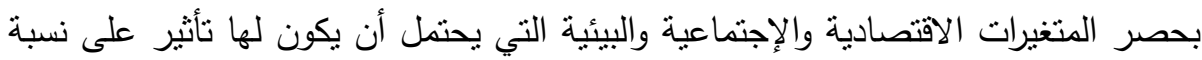
الفقر؛ للوقوف علي أهم المتغيرات (المحددات) المؤثرة علي نسبة الفقر وتتميتها ومحاولة التخفيف منها، وتم تجميعها في صورة البيانات الزمنية المقطعية(Panel Data)، وهي مزيج من بيانات السلاسل الزمنية والبيانات المقطعية، حيث يتم فيها جمع بيانات ظاهرة معينة

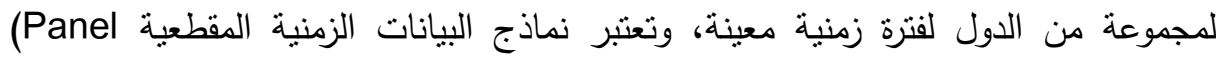
176

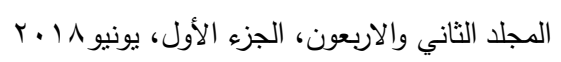


ذات أهمية؛ نظراً لأنها نأخذ في الاعتبار أثز تغير الزمن، وأثز تغير الاختلاف بين الوحدات المقطعية، على حد سواء، ويتفوق تحليل البيانات الزمنية المقطعية (Panel Data) علي تحليل بيانات السلاسل الزمنية (Time Series Data) أو البيانات المقطعية منفردة (Gujarati,D., N., (2004),) بالعديد من الإيجابيات ومنها (Cross Section Data) 1- التحكم في التباين الفردي الذي قد يظهر في حالة البيانات الزمنية أو المقطعية، والذي الإجياتي بفضي إلى نتائج متحيزة. r- تعطي البيانات الزمنية المقطعية معلومات أكثر ، من تلك التي تعطبها البيانات المقطعية أو الزمنية، مما يعني الحصول على تقديرات ذات ثقة أعلى. كما أن مشكلة الارتباط المشترك بين المتغيرات تكون أقل حدة من بيانات السلاسل الزمنية، بالإضافة إلي إنها تتميز عن غيرها بعدد أكبر من درجات الحرية. r- تسهم البيانات الزمنية المقطعية في الحد من إمكانية ظهور مشكلة المتغيرات المهملة، الناتجة عن خصائص المفردات غير المشاهدة، والتي تؤدي عادة إلى تقديرات متحيزة في في لهي

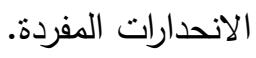

ع - تأخذ في الاعتبار ما يوصف بعدم التجانس أو الاختلاف غير الملحوظ والخاص بمفردات العينة

سواء المقطعية أو الزمنية. حيث يضع هذا نموذج في الاعتبار الاختلافات والآثار

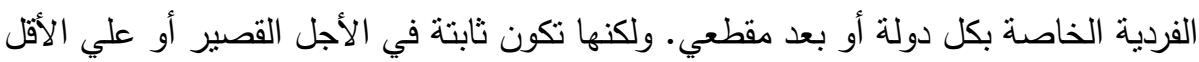

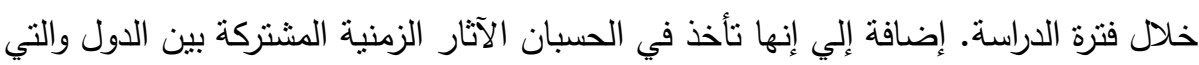
تنغير عبر الزمن. فقد قامت الدراسة بجمع البيانات الخاصة بعينة الدراسة لهجموعة من الدول، في صورة البيانات الزمنية المقطعية (Panel Data)، والتي تعتمد علي بيانات السلاسل الزمنية

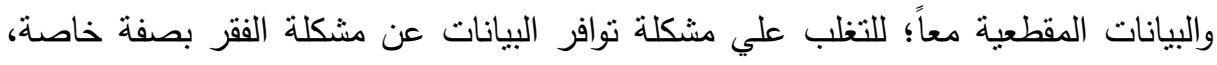
سواء من خلال العينة العشوائية أو السلاسل الزمنية فكلاهما يتطلب متطلبات تعجز الدراسة تواتئ

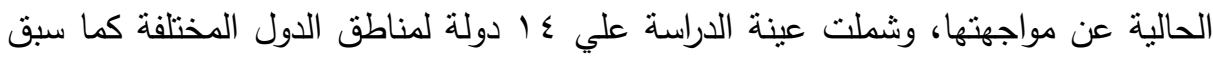

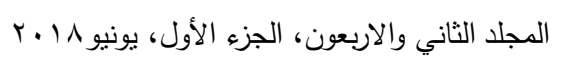


ذكرها سالفا؛؛ وهي تعكس البعد المقطعي (أثز مناطق العينة)، خلال فترة زمنية معينة موضع

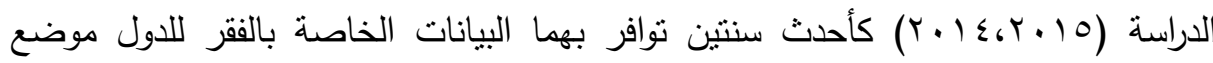

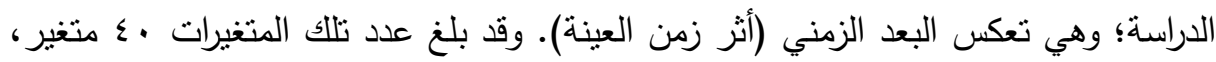

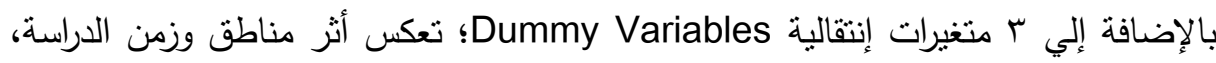
إثثان يعكسان مناطق الدول المختلفة، والثالث يعكس أثر عامي الدراسة.، استتاداً إلي مؤشرات

التتمية العالمية الخاصة بالدول موضع الدراسة بموقع البنك الدولي World Bank

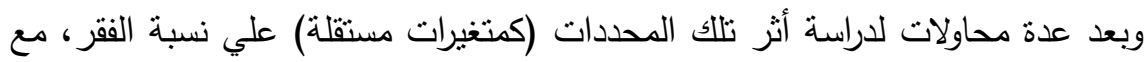

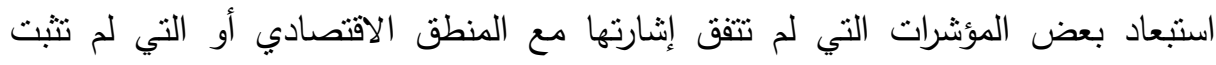

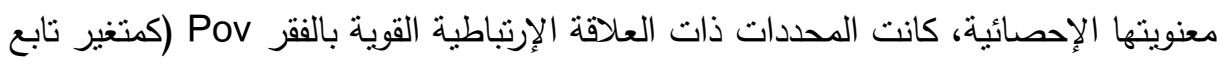
كما هو موضح بالجدول (0) علي النحو التالي: (Y)

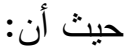

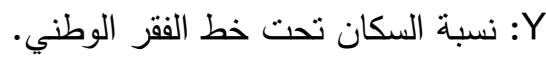

X1 نصيب الفرد من الناتج المحلي الإجمالي بالألف جنية، تعادل القوة الثرائية \$،

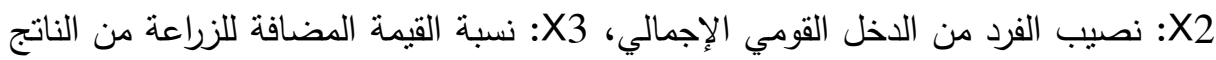

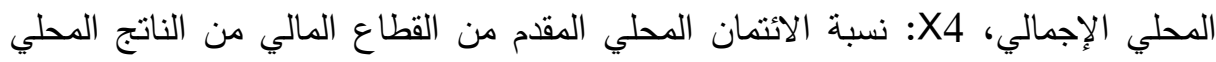
الإجمالي،X5: سكان المناطق الريفية (\% من إجمالي عدد السكان)، X6: نسبة الإعالة

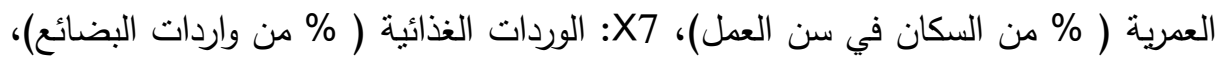

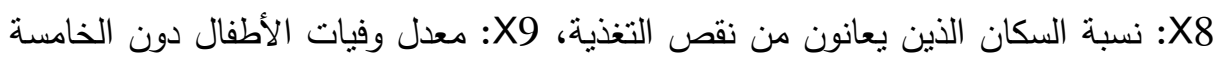

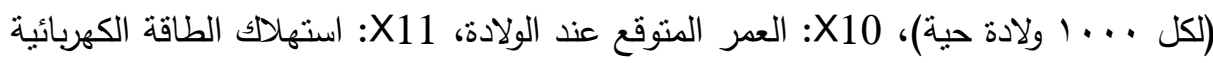
(كيلووات/ساعة للفرد)، X12: استخدام الطاقة (كجم/النفط للفرد)، X13: نسبة الإنفاق الاستهلاكي النهائي من الناتج المحلي الإجمالي، X14: نسبة الإنفاق الاستهلاكي النهائي

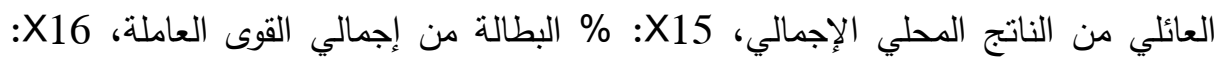

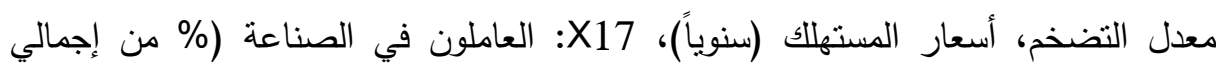
المشتغلين)، X18: السماد (كجم /هكتار من الأراضي الصالحة). 
محمد كامل إبراهيم ريحان وآخرون

جدول رقم(ه): بعض مؤشرات التتمية العالمية المختارة كمددات للفقر لدول عينة الدراسة

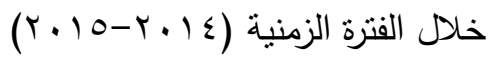

\begin{tabular}{|c|c|c|c|c|c|c|c|c|c|c|c|c|}
\hline $\mathrm{Xg}$ & $\mathrm{X}_{8}$ & $x 7$ & $\mathrm{X} 6$ & X5 & $X_{4}$ & $\mathrm{X}^{\mu}$ & $X^{Y}$ & $x_{1}$ & $\mathrm{Y}$ & السنورك & الشزئة & الشنطة" \\
\hline 36.3 & 15.1 & 16.6 & 52.6 & 65.7 & 59.7 & 15.5 & 3550 & 3342 & 24.3 & 2015 & \multirow{2}{*}{ بنجلادب } & \multirow{12}{*}{ وجنوب نُونُ } \\
\hline 38.6 & 16 & 16.9 & 53.8 & 66.5 & 59.8 & 16.1 & 3340 & 3132 & 31.5 & 2010 & & \\
\hline 27.3 & 7.9 & 10 & 49.2 & 46.3 & 46.8 & 13.9 & 10680 & 11062 & 11.2 & 2015 & \multirow{2}{*}{ إنتونسبا } & \\
\hline 28.3 & 7 & 9.6 & 49.6 & 47 & 43.4 & 13.7 & 10180 & 10537 & 11.3 & 2014 & & \\
\hline 45.2 & 14.5 & 5.8 & 52.2 & 67.3 & 76.1 & 17.5 & 6050 & 6139 & 20.4 & 2015 & \multirow{2}{*}{ انه } & \\
\hline 47.7 & 14.9 & 4.5 & 52.9 & 67.6 & 76 & 18 & 5610 & 5678 & 21.9 & 2011 & & \\
\hline 8.2 & 2.5 & 8.9 & 44.6 & 25.3 & 144.7 & 8.5 & 25860 & 26675 & 0.6 & 2015 & \multirow{2}{*}{ هالثئنا } & \\
\hline 8.1 & 2.6 & 8 & 45.2 & 26 & 140.5 & 8.9 & 24640 & 25487 & 0.6 & 2014 & & \\
\hline 28 & 13.8 & 11.7 & 58.2 & 55.6 & 59 & 10.3 & 8850 & 7335 & 21.6 & 2015 & \multirow{2}{*}{ القتبنين } & \\
\hline 28.8 & 14.3 & 12.2 & 58.7 & 55.5 & 55.9 & 11.3 & 8410 & 6938 & 25.2 & 2012 & & \\
\hline 81 & 19.9 & 12.1 & 65.3 & 61.2 & 48.8 & 25.1 & 5300 & 5010 & 29.5 & 2015 & \multirow{2}{*}{ باكسئل } & \\
\hline 83.3 & 20.7 & 11.7 & 65.8 & 61.7 & 47.5 & 24.9 & 5090 & 4821 & 36.3 & 2011 & & \\
\hline 23.7 & 4.5 & 19.4 & 61.8 & 56.9 & 95.3 & 11.3 & 10720 & 10771 & 27.8 & 2015 & \multirow{2}{*}{ كمر } & \multirow{6}{*}{ 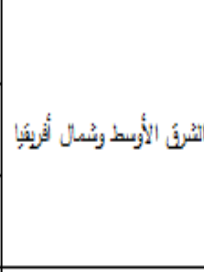 } \\
\hline 24.7 & 4.4 & 21.1 & 61.3 & 56.9 & 87.1 & 10.9 & 10160 & 10407 & 26.3 & 2012 & & \\
\hline 28 & 3.5 & 11.2 & 51.6 & 39.8 & 106.5 & 14.3 & 7610 & 7757 & 4.2 & 2015 & \multirow{2}{*}{ العنزب } & \\
\hline 29 & 4.1 & 12.2 & 51.7 & 40.3 & 111.7 & 13 & 7270 & 7448 & 8.9 & 2007 & & \\
\hline 14 & 5 & 11.2 & 45.6 & 33.2 & 89.9 & 11 & 11090 & 11469 & 15.2 & 2015 & \multirow{2}{*}{ كُوتس } & \\
\hline 14.6 & 4.5 & 9.7 & 45.1 & 33.4 & 86.5 & 9.8 & 10920 & 11326 & 20.5 & 2010 & & \\
\hline 38.2 & 20.2 & 7 & 63.7 & 31.5 & 67.1 & 13.2 & 6720 & 6969 & 38.6 & 2015 & \multirow{2}{*}{ بولئبا } & \multirow{10}{*}{ 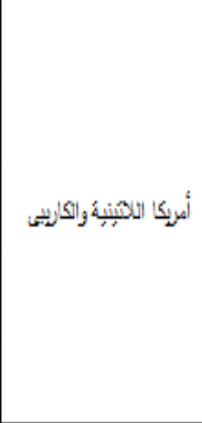 } \\
\hline 39.6 & 20.8 & 7.6 & 64.6 & 31.9 & 55.2 & 13 & 6320 & 6663 & 39.1 & 2014 & & \\
\hline 15.7 & 2.5 & 5.2 & 43.8 & 14.3 & 107 & 5 & 15280 & 15648 & 8.7 & 2015 & \multirow{2}{*}{ الثرلنيا } & \\
\hline 16.4 & 2.5 & 4.9 & 44.2 & 14.6 & 103.4 & 5 & 15870 & 16192 & 4.4 & 2014 & & \\
\hline 15.5 & 12.3 & 17 & 56.8 & 33.3 & 77.2 & 11.1 & 8000 & 8370 & 34.9 & 2015 & \multirow{2}{*}{ السنلالوز } & \\
\hline 16.1 & 12.1 & 16.3 & 57.7 & 33.7 & 73.7 & 11.3 & 7780 & 8119 & 31.8 & 2014 & & \\
\hline 19.4 & 14.8 & 18.1 & 59.8 & 45.3 & 58.1 & 13.6 & 4280 & 4600 & 63.8 & 2015 & \multirow{2}{*}{ نلـروس } & \\
\hline 20.1 & 15.8 & 18.1 & 61.3 & 45.9 & 59.5 & 13.7 & 4090 & 4457 & 62.8 & 2014 & & \\
\hline 20.6 & 12 & 8.7 & 56.6 & 40.6 & 49 & 19.2 & 8690 & 9218 & 26.6 & 2015 & \multirow{2}{*}{ بازبوابي } & \\
\hline 21.2 & 12.4 & 8.2 & 57.3 & 40.3 & 40.8 & 20.5 & 8510 & 8956 & 27.2 & 2014 & & \\
\hline
\end{tabular}


تابع جدول رقم(ه): بعض مؤشرات التتمية العالمية المختارة كمددات للفقر لدول عينة

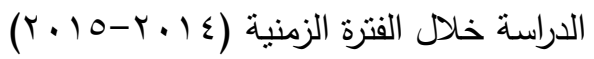

\begin{tabular}{|c|c|c|c|c|c|c|c|c|c|c|c|c|c|c|}
\hline$z$ & $\mathrm{D}_{21}$ & Dli & $\mathrm{x} 18$ & $\times 17$ & $\mathrm{x} 16$ & $\mathrm{x} 15$ & $\mathrm{x} 14$ & $\mathrm{x} 13$ & $\mathrm{x} 12$ & xll & $\mathrm{x} 10$ & السنوكاك & الثرئية & الثنطفة" \\
\hline 1 & 0 & 1 & 297.7 & 18.7 & 6.2 & 4.2 & 73.1 & 78.5 & 222.2 & 310.4 & 72.2 & 2015 & \multirow{2}{*}{ بنجالإب } & \multirow{12}{*}{ 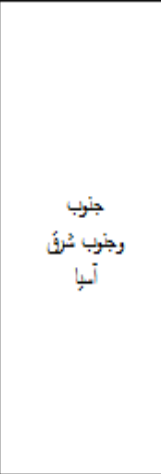 } \\
\hline 0 & 0 & 1 & 279.2 & 18.3 & 7 & 4.2 & 72.6 & 78 & 215.3 & 292.8 & 71.9 & 2010 & & \\
\hline 1 & 0 & 1 & 223 & 22.2 & 6.4 & 6 & 55.6 & 65.4 & 883.9 & 811.9 & 69 & 2015 & \multirow{2}{*}{ إندونسبا } & \\
\hline 0 & 0 & 1 & 231.9 & 20.3 & 6.4 & 5.9 & 56.7 & 66.1 & 863 & 7773.3 & 68.9 & 2014 & & \\
\hline 1 & 0 & 1 & 171 & 24.2 & 4.9 & 3.5 & 59.1 & 69.4 & 637.4 & 805.6 & 68.3 & 2015 & \multirow{2}{*}{ لين } & \\
\hline 0 & 0 & 1 & 163.5 & 24.1 & 6.6 & 3.5 & 58 & 68.4 & 606.9 & 765.6 & 68.1 & 2011 & & \\
\hline 1 & 0 & 1 & 1689.4 & 27.5 & 2.1 & 3.1 & 54.1 & 67.2 & 2967.5 & 4596.3 & 75.2 & 2015 & \multirow{2}{*}{ هلبزيا } & \\
\hline 0 & 0 & 1 & 1969.2 & 27.5 & 3.2 & 2.9 & 52.4 & 65.7 & 2955.8 & 4484.2 & 75.1 & 2014 & & \\
\hline 1 & 0 & 1 & 150.5 & 16.2 & 1.4 & 6.3 & 73.8 & 84.7 & 476.2 & 699.2 & 69 & 2015 & \multirow{2}{*}{ لنبين } & \\
\hline 0 & 0 & 1 & 166.5 & 16 & 4.1 & 6.6 & 72.5 & 83.1 & 454.9 & 685.7 & 68.9 & 2012 & & \\
\hline 1 & 0 & 1 & 137.3 & 19.7 & 2.5 & 5.9 & 79.8 & 90.7 & 484.4 & 471 & 66.3 & 2015 & \multirow{2}{*}{ باكسنّان } & \\
\hline 0 & 0 & 1 & 134.9 & 19.6 & 7.2 & 5.6 & 81 & 91.8 & 488.4 & 481.9 & 66.1 & 2011 & & \\
\hline 1 & 1 & 0 & 645.9 & 25.1 & 10.4 & 12.8 & 82.4 & 94.2 & 815 & 1657.8 & 71.3 & 2015 & \multirow[b]{2}{*}{ هصر } & \multirow{6}{*}{ 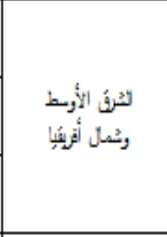 } \\
\hline 0 & 1 & 0 & 698.3 & 24.4 & 10.1 & 13.2 & 82.9 & 94.8 & 835.4 & 1658.6 & 71.3 & 2012 & & \\
\hline 1 & 1 & 0 & 71.1 & 20.5 & 1.6 & 9.7 & 57.5 & 76.8 & 553.1 & 901.1 & 75.5 & 2015 & \multirow{2}{*}{ للنزب } & \\
\hline 0 & 1 & 0 & 66.7 & 20.5 & 1 & 9.9 & 60.1 & 80 & 554.1 & 878.6 & 75.3 & 2007 & & \\
\hline 1 & 1 & 0 & 32.8 & 29.5 & 4.9 & 15.2 & 71 & 90.5 & 943.6 & 1444.1 & 75.5 & 2015 & \multirow{2}{*}{ نورنس } & \\
\hline 0 & 1 & 0 & 32.2 & 29.6 & 4.9 & 15.1 & 68.7 & 87.4 & 945.4 & 1417.9 & 75.3 & 2010 & & \\
\hline 1 & 0 & 0 & 9.1 & 20.9 & 4.1 & 3.1 & 68.4 & 85.9 & 788.8 & 752.7 & 68.7 & 2015 & \multirow{2}{*}{ بولبئا } & \multirow{10}{*}{ 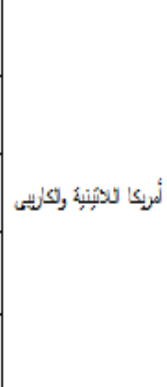 } \\
\hline 0 & 0 & 0 & 9 & 21 & 5.8 & 3.5 & 62.9 & 77.6 & 750.3 & 705.5 & 68.4 & 2014 & & \\
\hline 1 & 0 & 0 & 171 & 21.6 & 9 & 8.5 & 63.8 & 83.6 & 1484.9 & 2601.4 & 75.2 & 2015 & \multirow{2}{*}{ لبرازيل } & \\
\hline 0 & 0 & 0 & 188.8 & 22.3 & 6.3 & 6.8 & 63 & 82.1 & 1451 & 2551.4 & 75 & 2014 & & \\
\hline 1 & 0 & 0 & 134.9 & 20.2 & 1 & 7 & 90.2 & 102.2 & 647.3 & 939.2 & 73 & 2015 & \multirow{2}{*}{ لسلفادط } & \\
\hline 0 & 0 & 0 & 125.6 & 20.2 & 1 & 7 & 92.5 & 104 & 638.1 & 961.3 & 72.8 & 2014 & & \\
\hline 1 & 0 & 0 & 115.2 & 21.6 & 3.2 & 7.4 & 77.8 & 92.3 & 607.9 & 630.1 & 73.3 & 2015 & \multirow{2}{*}{ هنرو } & \\
\hline 0 & 0 & 0 & 139.8 & 20.9 & 6.1 & 5.5 & 80.3 & 95.7 & 600.6 & 653.6 & 73.1 & 2014 & & \\
\hline 1 & 0 & 0 & 97.6 & 19.6 & 3.1 & 5.3 & 69.6 & 82.4 & 788.7 & 1563.5 & 73 & 2015 & \multirow[b]{2}{*}{ بازجولب } & \\
\hline 0 & 0 & 0 & 105.3 & 18.9 & 5 & 6 & 69.1 & 81.4 & 764.1 & 1473 & 72.9 & 2014 & & \\
\hline
\end{tabular}

Y مؤشر نسبة الفقر بجميع دول العينة سجل لعامي 10 ـ ب كأحدث سنة، والعام الأخر

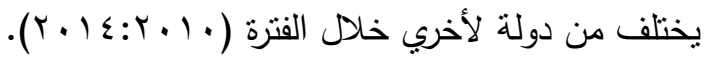

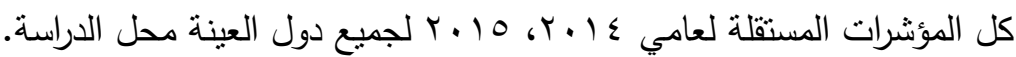
http://databank.worldbank.org , WDI المصدر: البنك الدولي 
وبدراسة هذا الجدول اتضح وجود دول ذات نسبة فقر أعلي من مصر وأخري أقل منها، وقد يعكس ذلك أهمية بعض المحددات في كل دولة. فبمقارنة محددات الفقر في مصر والدول

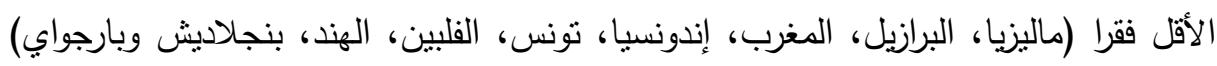

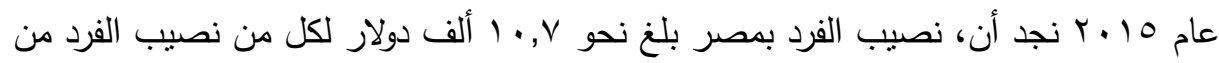

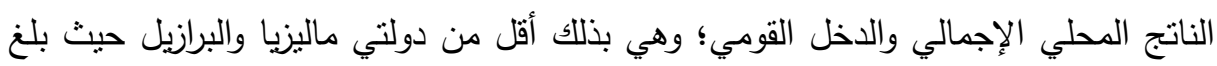

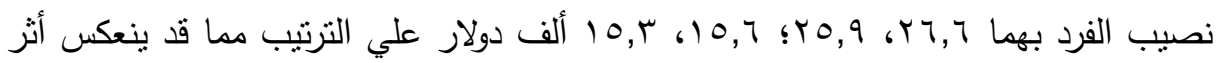
ذللك علي إنخفاض الفقر بهما عن مصر كما تتشابة باقي دول العينة في هذين المحددين.

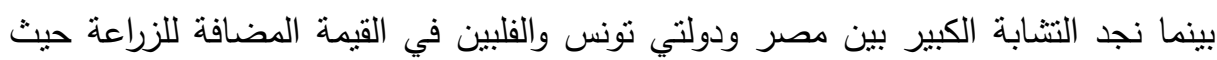

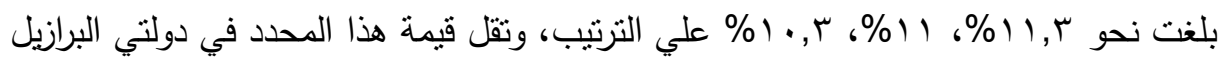

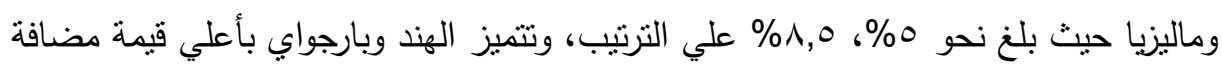

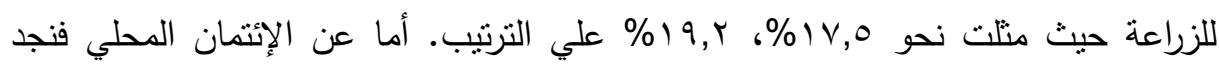

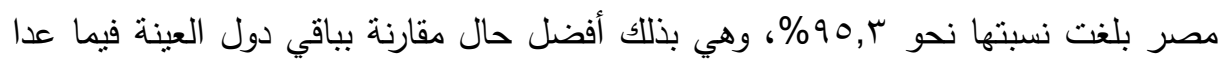

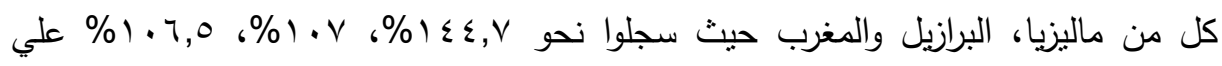

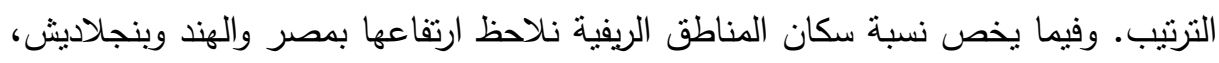

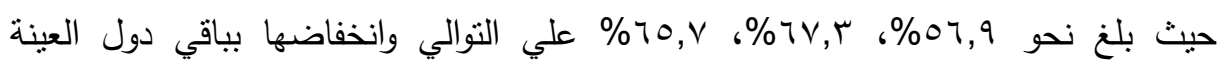

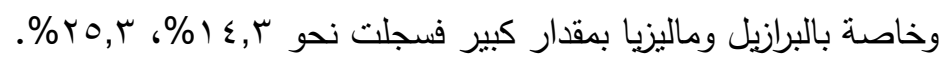

وانعكس ذلك علي معدل الإعالة حيث نجد أن مصر والهند وبنجلاديش يمثلوا أعلي باكي

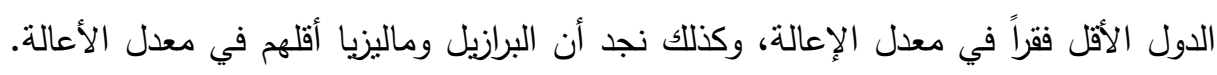

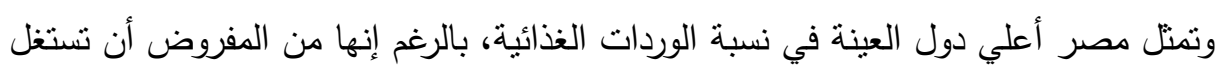
ميزة كثرة عدد سكان المناطق الريفية وتتمية الزراعة لتحقيق الاكتقاء الذاتي بها وقلة الواردات

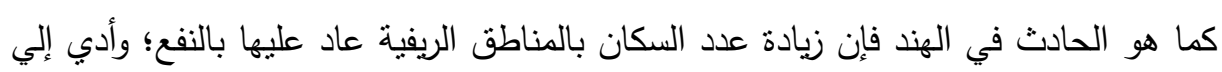
قلة الواردات الغذائية حيث أنها الدولة الأقل واردات بالعينة وبلغت واردتها من المواد العاد الغذائية

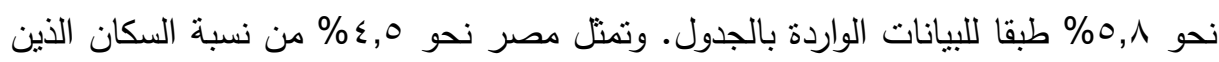

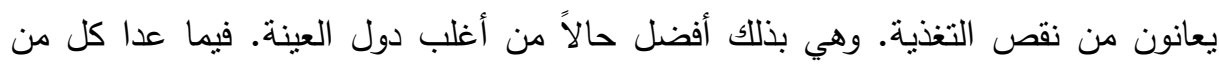

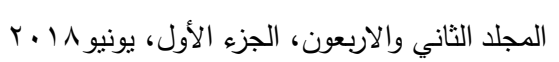




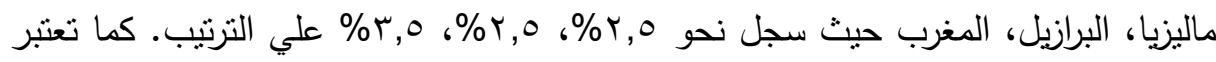

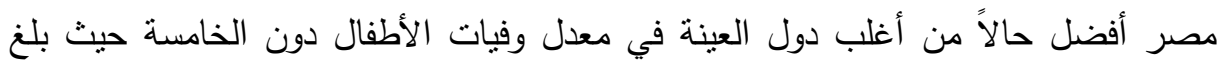

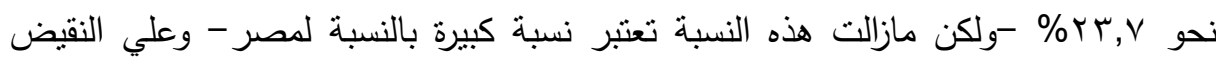

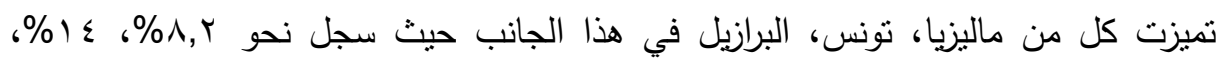

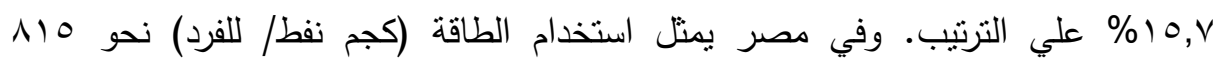

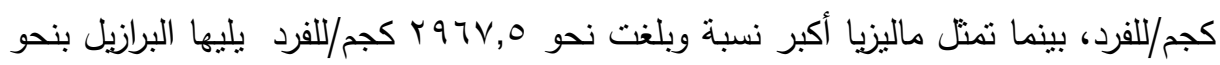

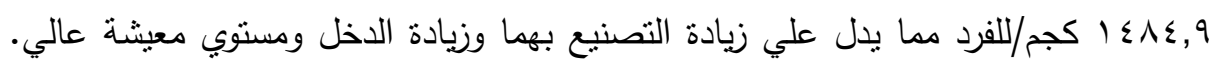

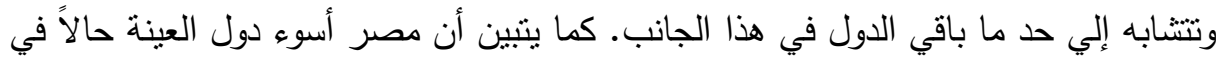
نسبة الإنفاق الاستهلاكي النهائي، والعائلي، ومعدل البطالة والتضخم.

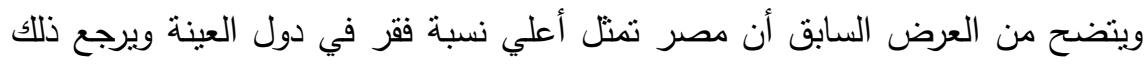
إلي: إنخفاض كل من نصيب الفرد من الناتج المحلي الإجمالي والدخل القومي والقيمة

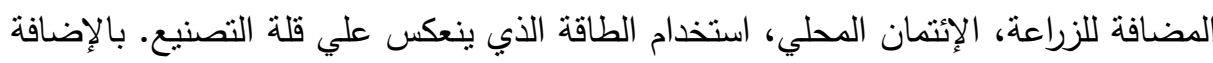

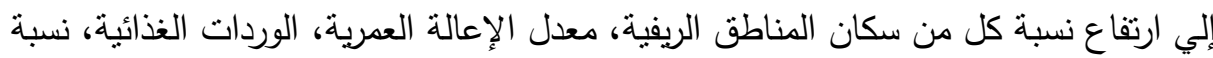
السكان الذين يعانون من نقص التغذية، معدل وفيات الأطفال، نسبة الإنفاق الاستهلاكي الإكي الهنه

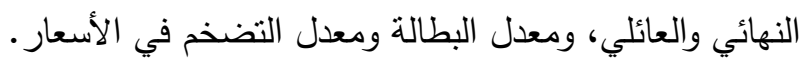
وبالمثل عند مقارنة محددات مصر مع محددات الدول الأعلي منها في نسبة الفقر فمدرل (باكستان، السلفادور، بوليفيا، هندروس) وجدنا أن مصر تمثل أقل نسبة فقر بين دول العينة ويرجع ذلك إلي إرتفاع نسبة كل من نصيب الفرد من الناتج المحلي الإجمالي والدخل القومي

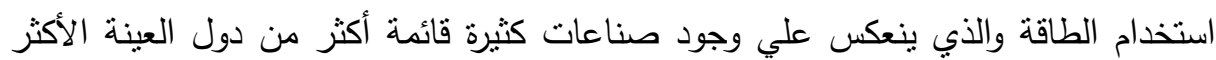

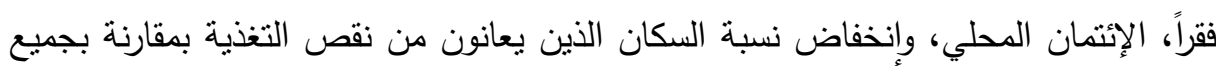
دول العينة. كما نجد أن مصر مازالت تعاني من ارتفاع سكان المناطق الريفية، معدل الإعالة

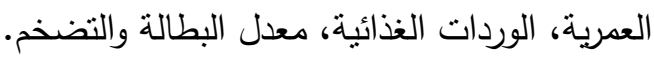
وعلي هذا لابد من البحث عن مصادر تؤدي إلي زيادة نصيب الفرد من الناتج المحلي الإجمالي والدخل القومي، وذلك سيتحقق من خلال الإهتمام بزيادة فرص العمل وجعل الأفراد 
منتجين وتحقيق الإكتفاء الذاتي وزيادة الصادرات من خلال إقامة الكثير من المشاريع الصغيرة. كما أن الإيتمان المحلي ساهم بنسبة كبيرة في إنخفاض الفقر في كل من ماليزيا،

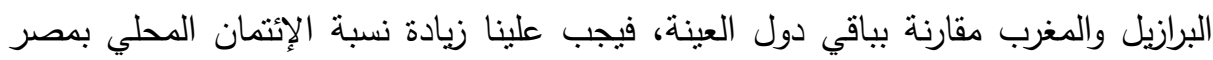

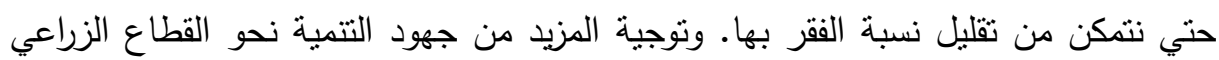
لأن الاغلبية العظمي من الفقراء تعيش في المناطق الزريفية التي يعتمد فيها علي الزراعة، وذلك من خلا الحرص علي إدخال التصنيع الزراعي في كل المنتجات الزراعية لزيادة القيمة

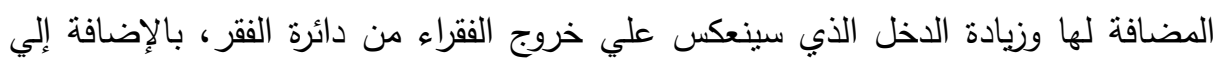
إعادة نوزيع السكان الريفيين إلي أراضي جديدة مستصلحة حتي نتمكن من تقليل عددهم

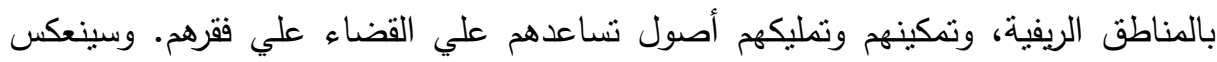
ذللك علي تقليل معدل الإعالة وقلة البطالة بالمجتمع المصري، كما إنه سيقلل من الواردات

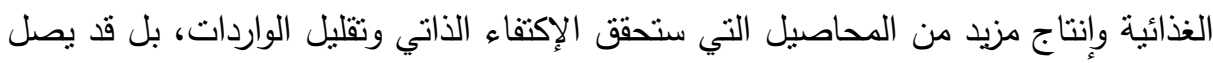

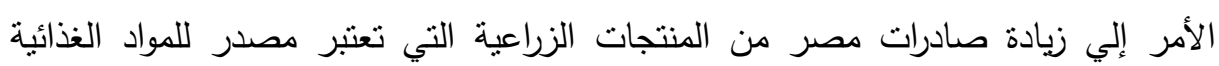

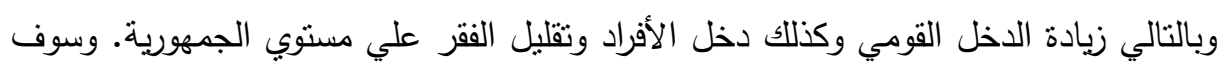
تحظي مصر كذلك بتقليل نسبة السكان الذين يعانون من نقص التغذية، الذي سيعود علي

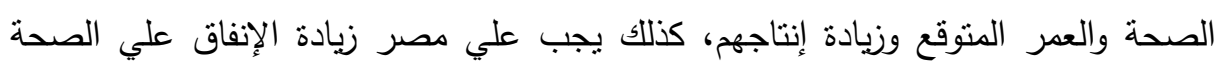

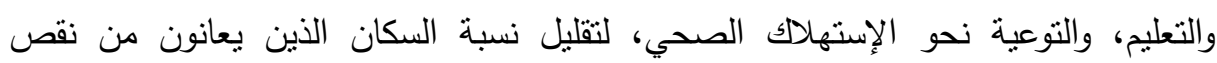

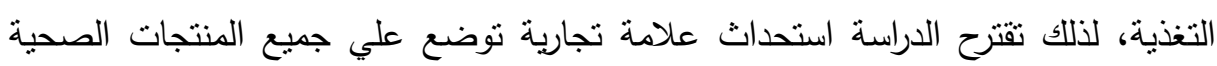
التي نستهدف شريحة الأطفال، مع تقديم الدعم لمنل هذه المنتجات بتخفيف الضرائب عليها إعتماداً علي فرض المزيد من الضرائب علي المنتجات غير الصحية، للإتجاه نحو الإستهلاك لكأل

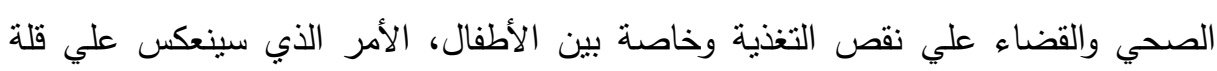

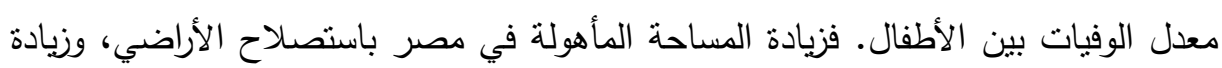

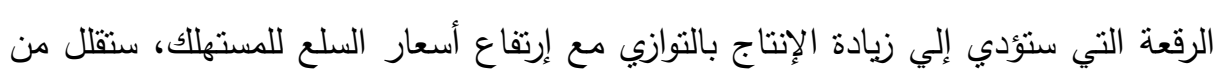

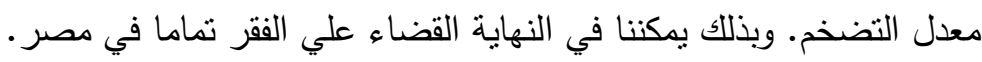


التقدير القياسي لمحددات الفقر في مصر والدول المختارة: وبإجراء طريقة المربعات الصغري العادية "OLS" علي هذه المتغيرات وبعد محاولات عديدة لتقدير هذا النموذج، تبين ولين أن الصورة اللوغاريتمية المزدوجة (كوب دوجلاس)؛ هي أفضل الصور الرياضية للنموذج المستخدم من حيث المنطق الاقتصادي والمعنوية الإحصائية، جاءت نتائج التحليل للنموذج النه المقدر بالمعادلة رقم (r) علي النحو التالي: Ln Pov ${ }_{i}=-0.13-0.247 \operatorname{Ln} X_{1}-0.472 \operatorname{Ln} X_{3}+0.772 \operatorname{Ln} X_{5}$

$$
(-0.10) \quad(-2.4)^{* *} \quad(-3.6)^{* *}(4.4)^{* *}
$$

$+1.060 \operatorname{Ln} \mathrm{X}_{8}+0.781 \operatorname{Ln} \mathrm{X}_{15}+0.215 \operatorname{Ln} \mathrm{X}_{16}$ $(10.5)^{* *} \quad(8.2)^{* *} \quad(5.6)^{* *}$ $-0.9 D_{1 i}-0.4 D_{2 i}+0.5 Z$

$$
\begin{array}{llll}
\mathrm{R}^{2}=0.99 & \mathrm{R}^{12}=0.98 & \mathrm{~N}=28 & \mathrm{~F}=171^{* *} \\
& & &
\end{array}
$$

نماند: متغير انتقالي يعكس أثز منطقة شرق وجنوب آسبا ويأخذ ا للدول الممثلة لهذه الدنطقة، و صفراً لباقي الدول الأخري، D2i: متغير انتقالي يعكس أثر منطقة الثرق الأوسط

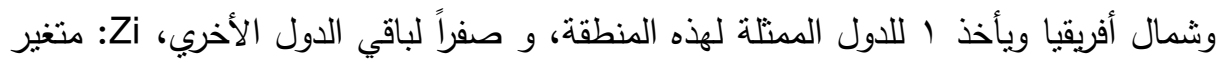
انتقالي يعكس أثز الزمن ويأخذ ا لسنة 10 ـ ب كأحدث سنة تثوافر بها البيانات، وصفراً للعام الأخر.

ويتضح من دراسة المعادلة (1): منطقية تأثير جميع المتغيرات المستقلة (المحدات) علي نسبة الفقر • حيث تحققت العلاقة العكسية بين نسبة الفقر ونسبة كل من نصيب الفرد من

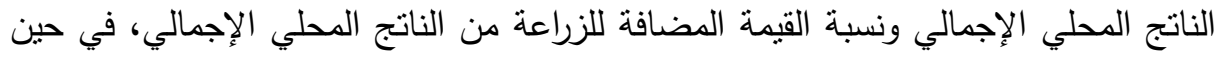
تحققت العلاقة الطردية بين نسبة الفقر وكل من نسبة السكان الذين يعانون من نقص التغذية،

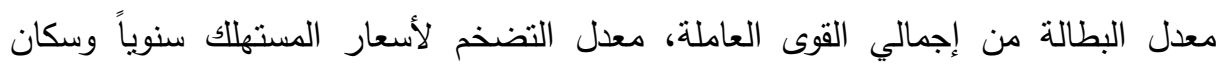
المناطق الريفية، وهذا ما يتفق مع المنطق الاقتصادي. بالإضافة إلي ثبوت المعنوية

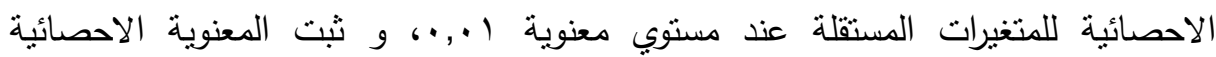

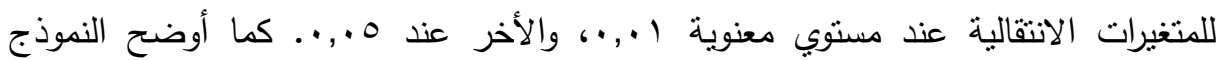


المقدر أن أهم العوامل (المحددات) التي تؤثر علي نسبة الفقر فيما بين الدول النامية المختارة بعينة الدراسة هي: نسبة السكان الذين يعانون من نقص التغذية، معدل البطالة، معدل التضخم، سكان المناطق الريفية، نسبة القيمة المضافة للزراعة من الناتج المحلي الإجمالي ثن نصيب الفرد من الناتج المحلي الإجمالي، علي الترتيب وذلك وفقاً لمعنوية التأثير الخاصة لاصنة بكل منهم.

ومن خلال قيم المعالم المقدرة بالنموذج في الصورة اللوغاريتمية المزدوجة التي تثير إلي المرونات المختلفة اتضح أن؛ نسبة التغير في الفقر للتغير في نسبة نصيب الفرد من الناتج المحلي الإجمالي بلغت نحو (Y0, .--)؛ وهذا بعني أن زيادة نسبة نصيب الفرد من الناتج

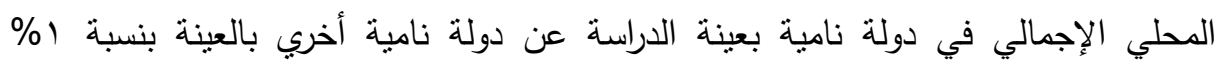

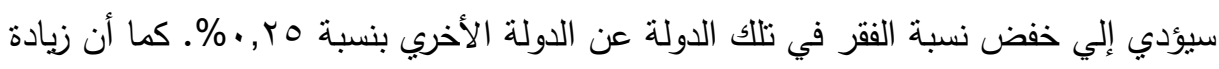

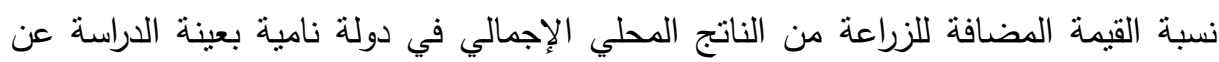
دولة نامية أخري بالعينة بنسبة ا \% سيؤدي إلي خفض نسبة الفقر في تلك الدولة عن الدولة

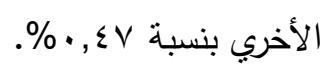

في حين بلغت نسبة التغير في الفقر إلي التغير في نسبة كل من السكان الريفيين،

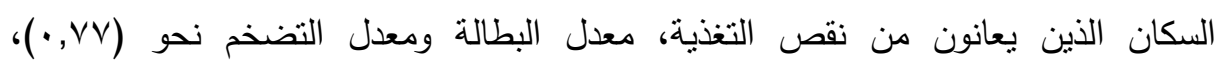

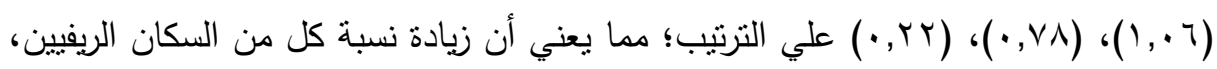
السكان الذين يعانون من نقص التغذية، معدل البطالة ومعدل التضخم في دولة نامية بعينة

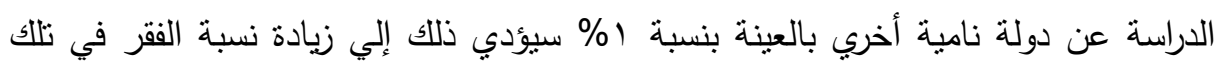

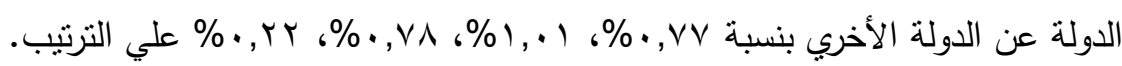

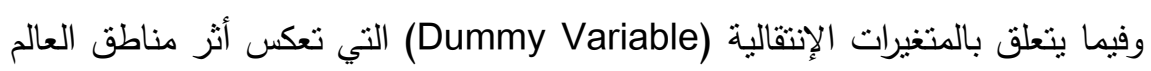
الثلاثة التي تمنلاها دول العينة ؛ فتبين ثبات المعنوية الإحصائية للمتغيرين الانتقاليين اللذان

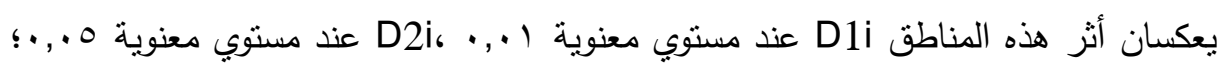
وهذا يعني وجود اختلاف جوهري في نسبة الفقر بدول منطقتي شرق وجنوب آسيا ومنطقة الثرق الأوسط وشمال أفريقيا بالعينة عن نسبة الفقر في منطقة أمريكا اللاتينية والكاريبي.

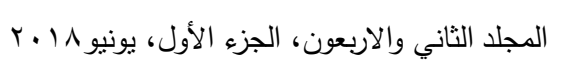


بينما لم يثبت المعنوية الإحصائية للمتغير الذي يعكس أثر زمن الدراسة "Zi"؛ بمعني عدم وجود اختلاف جوهري في نسبة الفقر فيما بين الدول النامية بعينة الدراسة خلال عام 10 ــ بـ.

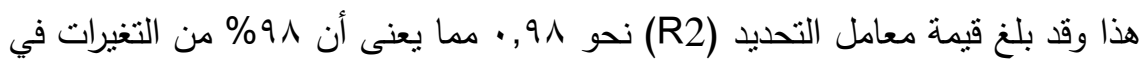

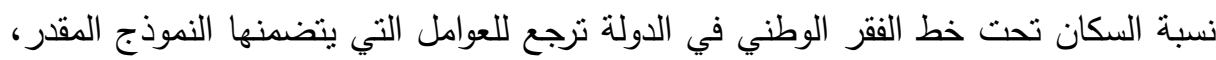

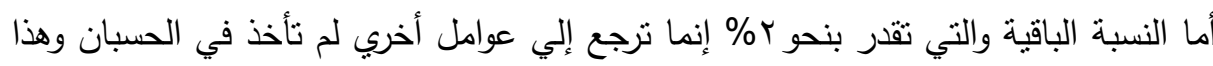

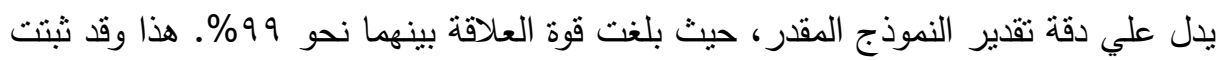
معنوية النموذج المستخدم للقياس بصفة عامة وذللك باستخدام قيمة (F) المحسوبة. امكانية خفض الفقر في الدول النامية موضع الاراسة:

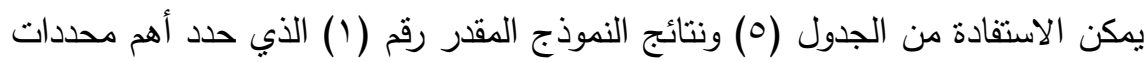
الفقر فيما بين الدول النامية موضع الدراسة ومن بينهم مصر ؛ في تقدير نسبة تأثير المحددات

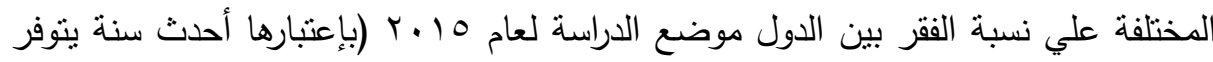

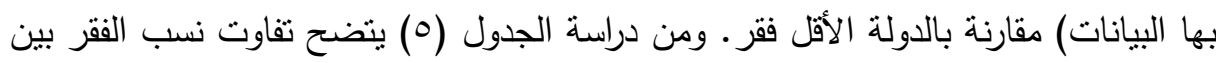

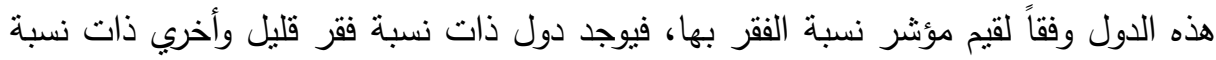

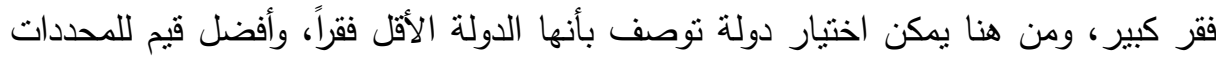

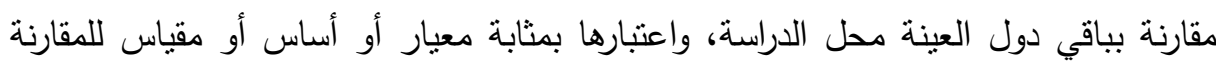

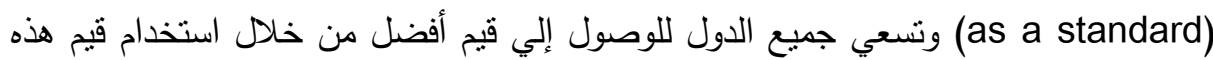

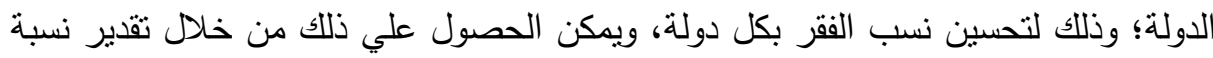
ما يرجع إلي كل محدد علي حدا من هذا الفرق بين الدولتين (الأقل والأكثر فقراً) باستخدام

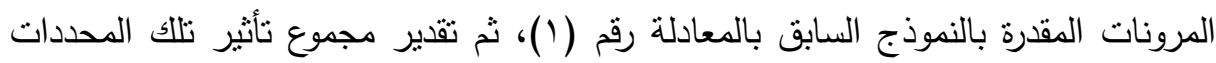
من هذا الفرق. وبالتالي يمكن الحصول علي النسبة المتوقعة لخفض نسبة الفقر في الدول النامية محل الدراسة. فضلاً عن حساب الفرق في نسبة الفقر بين الدول النامية الأكثر فقراً والدولة النامية الأقل فقراً. فعلي سبيل المثال؛ يتم تقدير الفرق في نسبة كل محدد من تلاك فلك

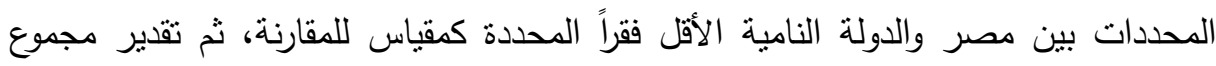
النسب المئوية للفروق في نصيب الدولتين من تلك المحددات المرجحة بمرونتها، وبالتالي 
معرفة كم من هذا الفرق (كنسبة مئوية) يعزي إلي محددات النموذج؛ أي الحصول علي النسبة

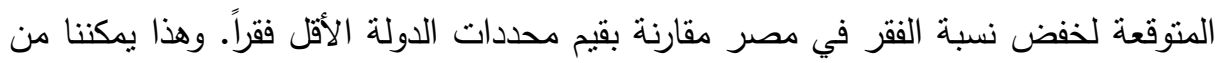
الوقوف علي القيمة المتوقعه لنسبة الفقر المحسنه المراد الوصول إليها في مصر ـ ثم تحليل وتوزيع هذه النسبة بين المحددات كل علي قدر أهميته ومساهمته في هذه النسبة من الفرق في مصر (الدولة الأكثر فقراً). وهكذا يكرر هذا التحليل لكل دولة من الدول النامية المختلفة موضع الدراسة للحصول علي نسبة الفقر المحسنة المتوقعة. فيما عدا الدولة التي نم اختيارها بأنها الدولة الأقل فقراً والتي تعتبر بمثابة معيار أو أساس أو مقياس (as a standard).

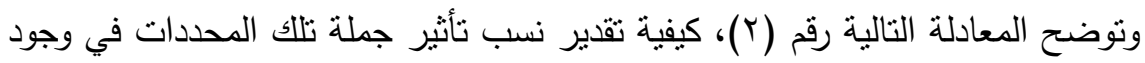
الاختلاف في نسبة الفقر بين الدول النامية موضع الدراسة ( بمعني \% لما برجع إلي جملة

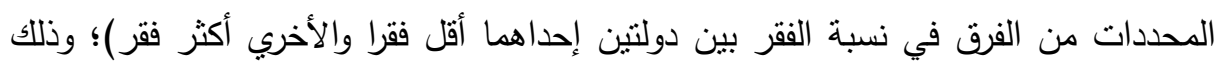
من خلال مجموع النسب المئوية للفروق في نصيب الدولتين من المحددات المختارة بالعينة مرجحة بمرونتها، والتي بمكن صياغتها كالتالي:

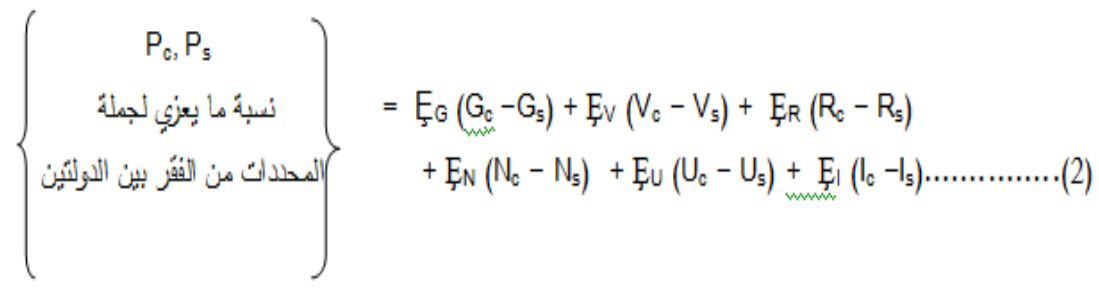

$$
\begin{aligned}
& \text { حيث أن: } \\
& \text { نسبة السكان تحت خط الفقر الوطني في الدولة: P }
\end{aligned}
$$

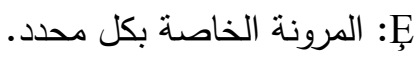

$$
\begin{aligned}
& \text { G: نصيب الفرد من الناتج المحلي الإجمالي لكل دولة، (GDP). } \\
& \text { ن نسبة القيمة المضافة للزراعة من الناتج المحلي الإجمالي لكل دولة. } \\
& \text { :R سكان المناطق الريفية (\% من إجمالي عدد السكان) لكل دولة. } \\
& \text { N نسبة السكان الذين يعانون من نقص التغذية لكل دولة. } \\
& \text { U نسبة البطالة من إجمالي القوى العاملة لكل دولة. }
\end{aligned}
$$

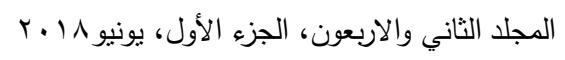




$$
\text { ا: معدل التضخم في أسعار المستهلك (سنوياً) لكل دولة. }
$$

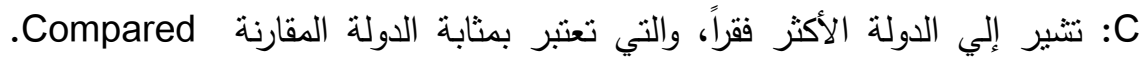

Country

S: نتير إلي الدولة الأقل فقراً، والتي تعتبر كمقياس Standard Country كأساس

$$
\text { المقارنه، التي تسعي باقي الدول للوصول اليه. }
$$

والجدير بالذكر أنه من الصعب تحديد دولة واحدة فقط من ضمن الدول النامية محل

الدراسة كدولة قياسية في كل المؤشرات السبعة سابقة الذكر ولذلك تم أختيار أفضل دولتين يتمبزوا بأنهم أقل في نسبة الفقر مقارنة بباقي الدول النامية محل الدراسة، فوجد أنهم: دولة ماليزيا، البرازيل هما صاحبة أقل نسبة فقر بين الدول محل الدراسة؛ حيث بلغت قيمة نسبة بله

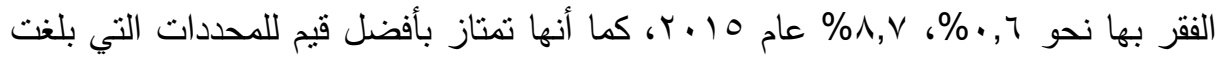

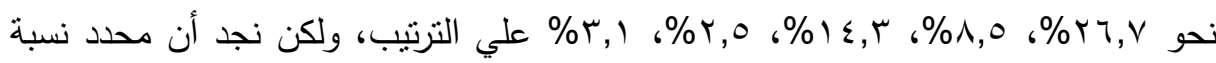

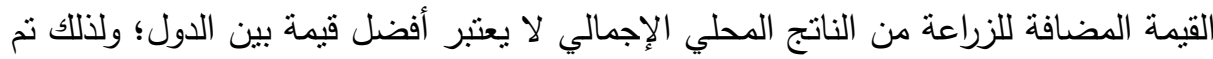

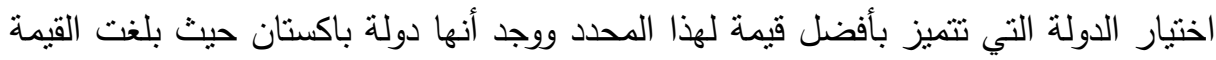

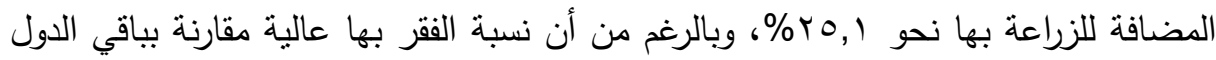

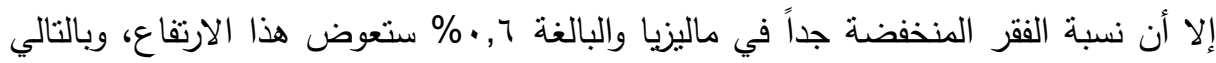

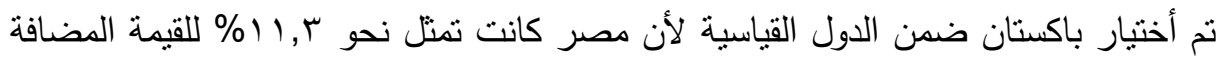

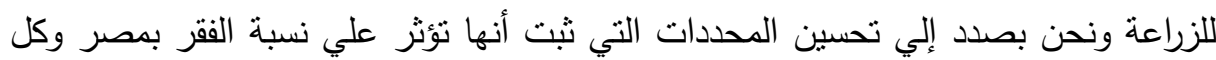

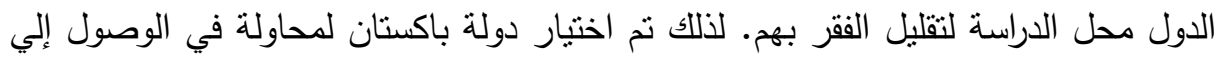
أفضل قيمة للمحدد. وبالتالي أصبح لدينا ثناثة دول بمثابة دول قياسية تحاول كل الدول

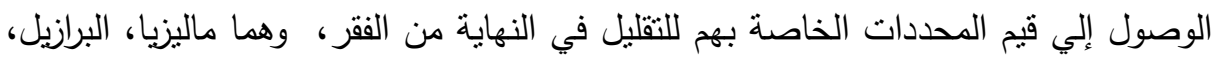
باكستان كدول قياسية (معيارية) كأساس للمقارنة مع باقي الدول النامية الأخري الأكثر فقراً

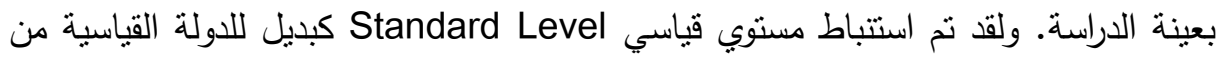
هذه الدول الثلاثة كالتالي: فيما يخص مؤشر نسبة الفقر "المتغير التابع" فإنه يمنل المتوسط لئه الهندسي لنسب الفقر الخاصة بالدول الثلاثة، أما بالنسبة لباقي المتغيرات "المستقلة"، فتم 
اختيار أفضل قيمة لكل محدد من بين هذه الدول الثلاثة. ومن ثم فقد بلغت قيم المحددات

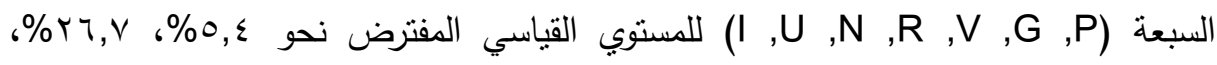
\%ro,1

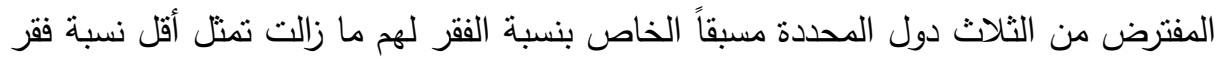

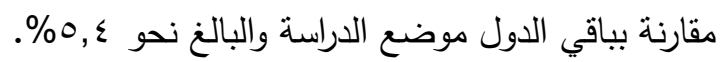

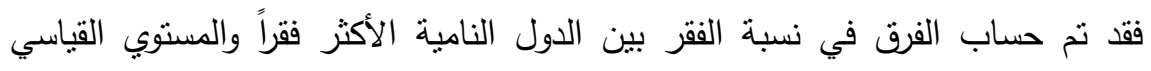
المفترض (الدولة الأقل فقراً)، وتقدير الفرق في نسبة كل محدد من ثلإك المحددات بين دول

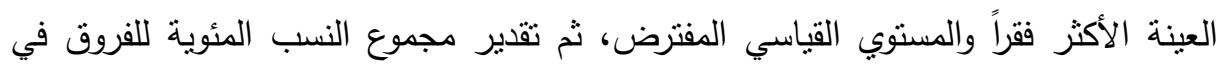
نصيب الدولتين من تلك المحددات المرجحة بمرونتها، والحصول علي النسبة المتوقعة لخفض نسبة الفقر بكل دولة مقارنة بقيم محددات المستوي القياسي المفترض. وأخير الوصول إلي لني القيمة المتوقعه لإمكانية خفض نسبة الفقر (المحسنه) المراد الوصول إليها بكل دول العينة

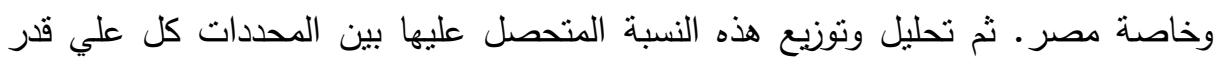

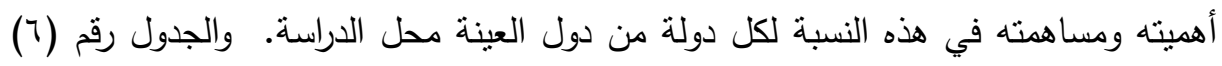
يوضح النتائج المتحصل عليها من هذا التقدير . مع ملاحظة أنه عند تقدير مجموع النسب المئوية للفروق في نصيب الدولتين من

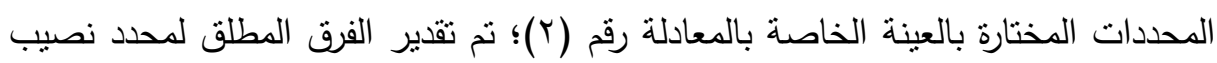

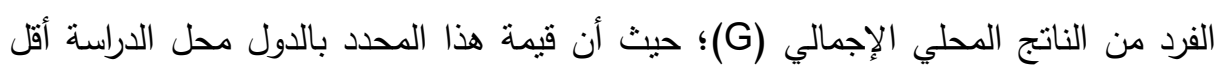

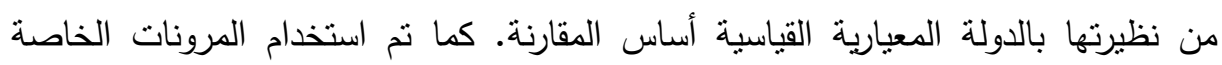
بنسبة نصيب الفرد من الناتج المحلي الإجمالي (G) ونسبة القيمة المضافة للزراعة كرقم

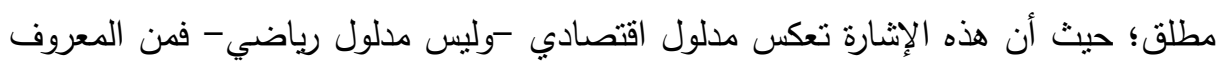

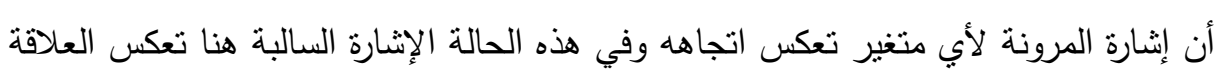

$$
\text { العكسية بين هذان المتغيران ونسبة الفقر. }
$$

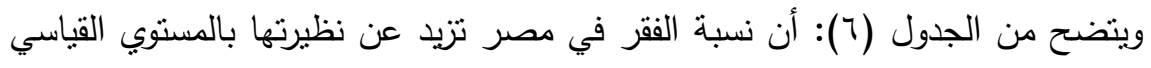

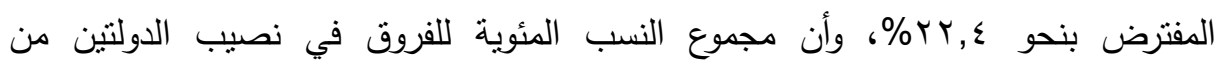

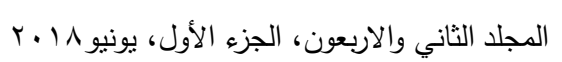




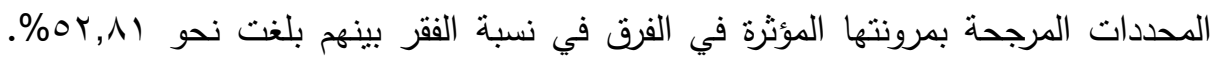
ومن هنا تمكنا من خفض نسبة الفقر فأصبحت نسبة الفقر المتوقعة عند مقارنة مصر

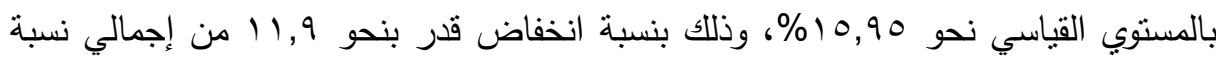

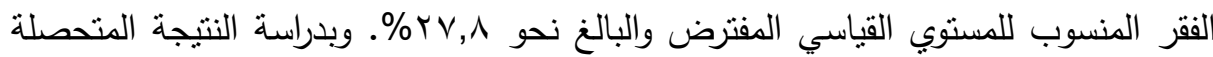
من الفرق في نسبة كل محدد من تلك المحددات علي حدي بين مصر والمستوي القياسي؛

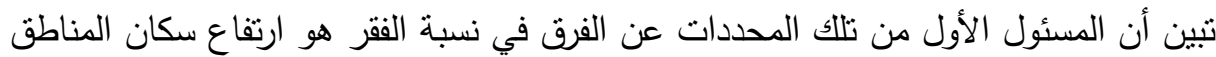

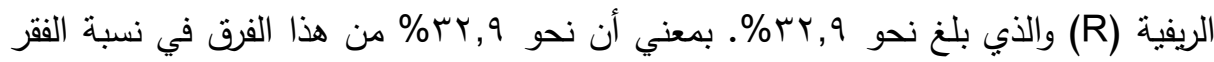
بين مصر والمستوي القياسي ترجع إلي ارتفاع سكان المناطق الريفية. بينما كان انخفاض

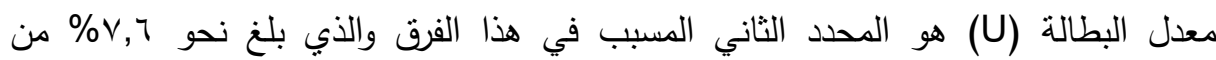

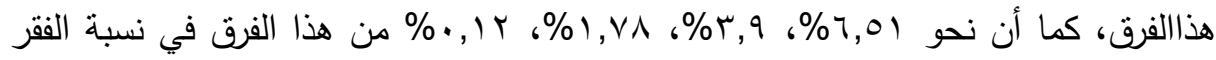
يرجع إلي ارتفاع نسبة كل من نسبة القيمة المضافة للزراعة(V)، ونصيب الفرد من الناتج

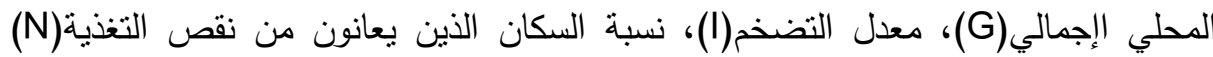
علي الترتيب. ومن هنا يجب علي الدولة أن تتنهج سياسة حسن استخدام الموارد بكفاءة

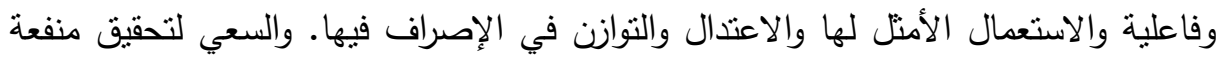
الإنسان بتحقيق تتمية مستدامة هدفها حفظ حقوق الأفراد في الحاضر والمستقبل. كما أظهر نفس الجدول أن: نسبة الفقر في بنجلاديش نزيد عن نظيرتها بلهوف بالمستوي

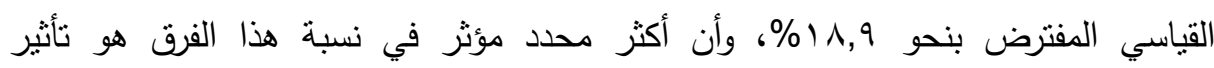
انخفاض سكان المناطق الريفية (R) بمقدار بلغ نحو 39.7\%، من هذا الفرق في نسبة الفقر

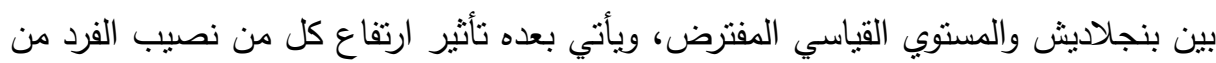

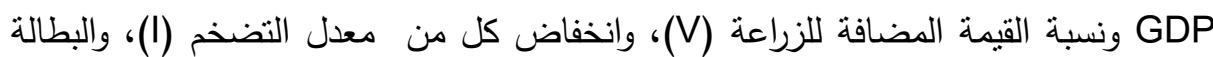

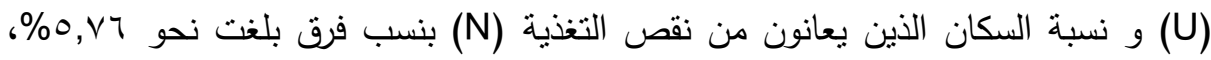

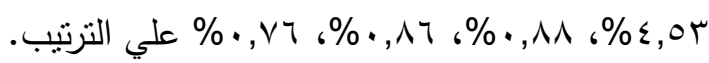
وأن جملة تأثثر هذه المحددات مجتمعة من الفرق في نسبة الفقر بين بنجلاديش

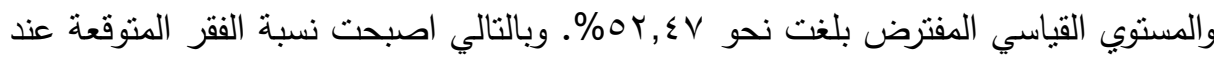




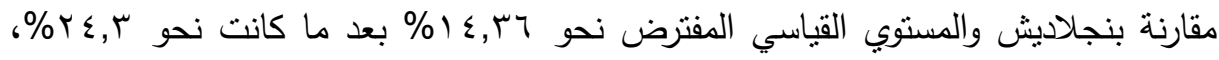
وذلك بنسبة انخفاض قدر بنحو ؟9,9 من إجمالي نسبة الفقر المنسوبة إلي المستوي القباسي

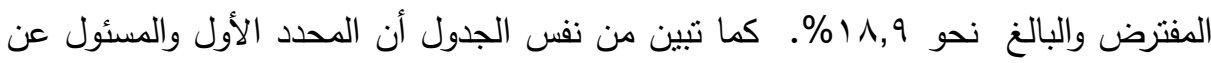

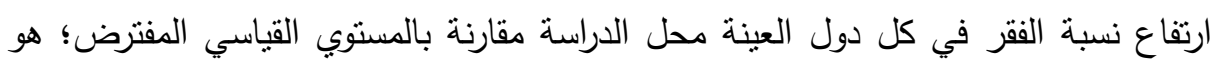
ارتفاع نسبة سكان المناطق الريفية. جدول رقم(؟): النسب المئوية المتوقعة للفرق بين المحددات بكل دولة ونسبة محددات الدولة القياسية، ومجموعها عام 10

\begin{tabular}{|c|c|c|c|c|c|c|c|c|c|c|}
\hline \multicolumn{8}{|c|}{ 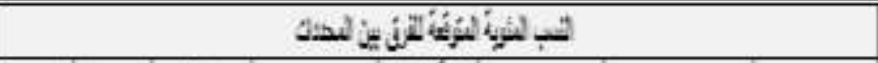 } & \multirow[b]{2}{*}{ 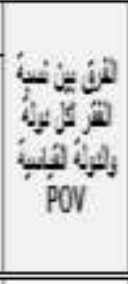 } & \multirow[b]{2}{*}{$4 y$} & \multirow[b]{2}{*}{$\frac{10}{4}$} \\
\hline$\frac{\mathrm{m}}{\mathrm{j}}$ & (2) & $\frac{j}{j}$ & (4) & 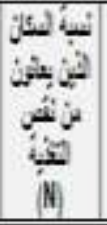 & 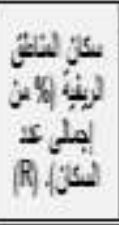 & 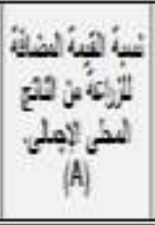 & 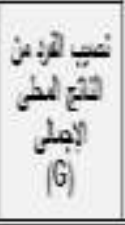 & & & \\
\hline 9.94 & 58 & 188 & 0.86 & 0.76 & 368 & 453 & 576 & 189 & 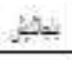 & \multirow{4}{*}{ نج } \\
\hline 218 & 3736 & 092 & 2.65 & 0.32 & 247 & 5.3 & 386 & 58 & ثلرب & \\
\hline 7.7 & 5111 & 1060 & 0.31 & 0.7 & 492 & 33 & 507 & 158 & 4 & \\
\hline 76 & 488 & " & 230 & 668 & 31.88 & 699 & 478 & $15:$ & $=$ & \\
\hline 115 & 581 & $1 \times$ & 758 & 0.12 & 228 & 651 & 393 & 24 & $j$ & \multirow{3}{*}{$\begin{array}{l}12 \\
-3 \\
-4 \\
4 \\
4\end{array}$} \\
\hline 098 & $3+67$ & . & 315 & 0.06 & 196 & 5n & 467 & 28 & لتزب & \\
\hline 3.46 & 350 & 06 & $9-5$ & 015 & 1459 & 666 & 3.6 & 98 & 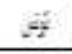 & \\
\hline 839 & 53 & 26 & 000 & $1 / 5$ & 133 & 52 & 487 & E. & ty & \multirow{4}{*}{ 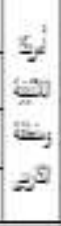 } \\
\hline 86 & 3.4 & ${ }^{\prime}$ & 305 & 0.59 & 1467 & 6.1 & 452 & 3.5 & سلتر & \\
\hline 29 & $3 B$ & o.t. & 336 & 674 & 393 & 56 & 5.5 & 38,4 & كاني. & \\
\hline 635 & 1398 & 022 & $1 n$ & 057 & 230 & $2 \pi$ & 431 & 212 & t & \\
\hline
\end{tabular}

* تشير إلي أن قيمة هذا المحدد أحسن حالًا من نظيرة بدول المستوي القياسي

$$
\text { المفترضة. }
$$

المصدر : حسبت من الجدول رقم(0) والمعادلة رقم (Y). 
أما المحدد الذي يلية يختلف من منطقة لآخري، حيث يتضح أن المحدد الثاني المسئول

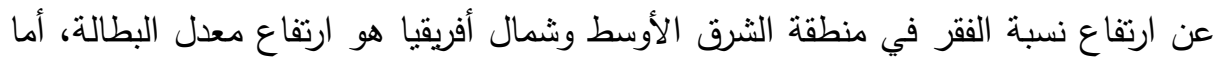
منطقتي شرق وجنوب آسيا وأمريكا اللاتينية ومنطقة الكاريبي فكان انخفاض نسبة الاضنية القيمة

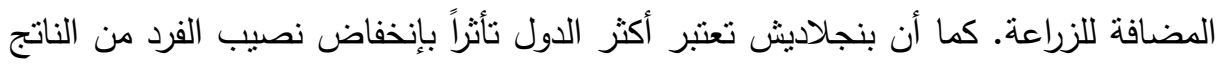

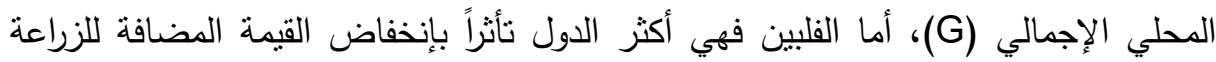

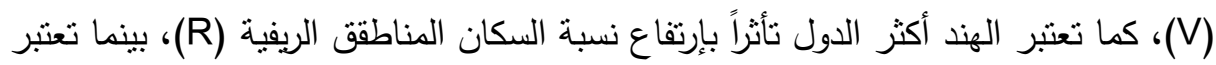

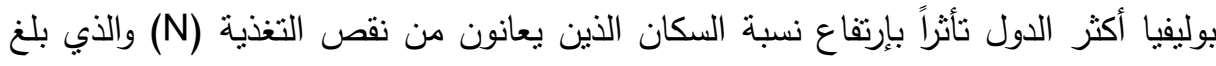

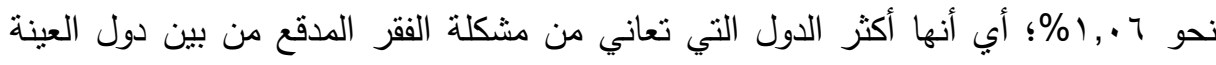
مقارنة بباقي دول عينة الدراسة، كما تعتبر نونس صاحبة أكبر تأثر من نسبة ارتفاع معدل البطالة المسبب لإرتفاع الفقر حيث بلغ نحو 0 ؛, 9\% مقارنة بباقي دول العينة محل الدراسة.

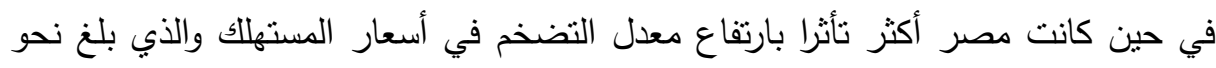
\% $1, \vee \wedge$

ويوضح الجدول التالي رقم (V)؛ امكانيات خفض نسبة الفقر في الدول محل الدراسة،

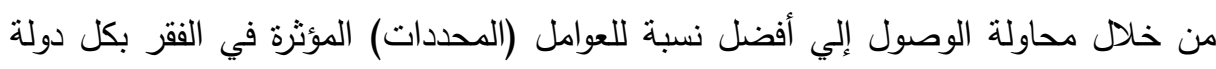

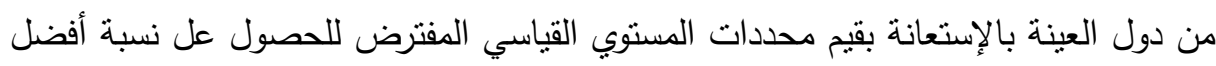
للفقر ومنخفضة عن القيم الحالية.

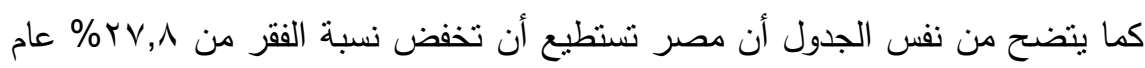
10 10,90 10,9 (وهذا ناتج من انخفاض نسبة الفقر بقيمة قدرها نحو

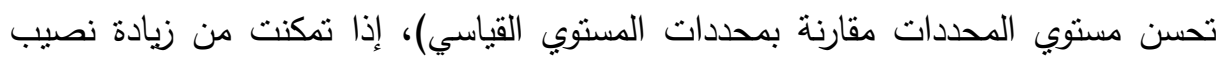

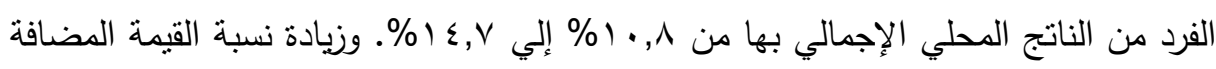

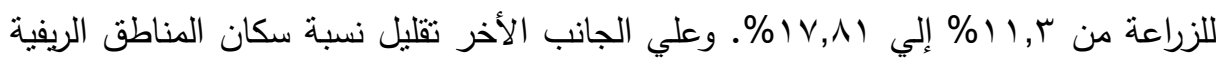

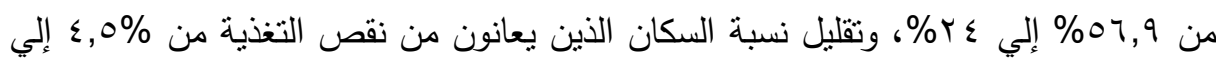

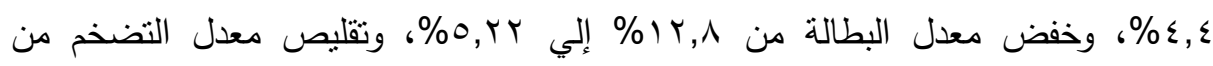

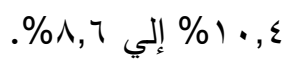




\section{النمائية}

1- ازدياد نسبة وأعداد الفقر والفقراء تحت خط الفقر القومي في مصر من سنة لأخري، علي الرغم من الجهود التتموية المبذولة. فقد تزايد عدد ونسبة الفقراء من ^, ب ا مليون نسمة،

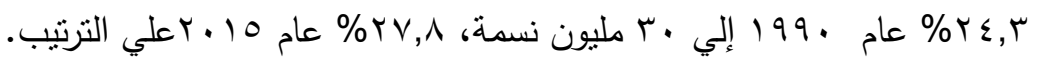

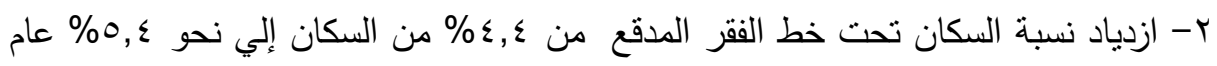

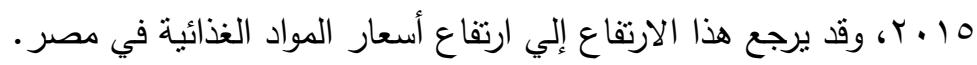
جدول رقم(V): امكانيات خفض نسبة الفقر في الدول محل الدراسة مقارنة بالدولة القياسية ماليزيا عام 10

\begin{tabular}{|c|c|c|c|c|c|c|c|c|c|c|c|c|c|c|c|}
\hline \multicolumn{12}{|c|}{$3-4 x y-2$} & \multirow{2}{*}{\multicolumn{2}{|c|}{ 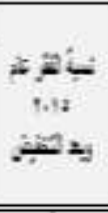 }} & \multirow{3}{*}{4} & \\
\hline \multicolumn{2}{|c|}{$\frac{1}{4-1}$} & \multicolumn{2}{|c|}{ ب0 } & \multicolumn{2}{|c|}{$\begin{array}{l}2 x-4 \\
0 y \leq 4 \\
\text { ant }\end{array}$} & \multicolumn{2}{|c|}{ 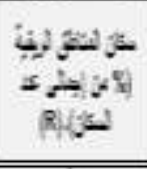 } & \multicolumn{2}{|c|}{ 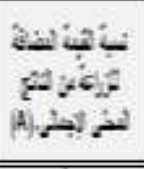 } & \multicolumn{2}{|c|}{$\underset{|0|}{A+1}$} & & & & \\
\hline$=$ & $\begin{array}{l}51 \\
1 \\
13\end{array}$ & $\Rightarrow$ & الدية & $=$ & لدئ & $=$ & لئ & $=$ & الد & $=$ & 32 & $=$ & ty & & \\
\hline 538 & 62 & 334 & 42 & 634 & LII & 2652 & 55.7 & 2008 & 155 & 0.17 & 33 & 1136 & 143 & $x_{3}$ & \\
\hline 548 & 64 & 374 & 6 & 751 & 78 & 8.5 & 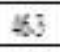 & 19.19 & 1.5 & $1-7$ & $11 \mathrm{~d}$ & 902 & 11. & $\rightarrow$ & \\
\hline 45 & 49 & 319 & 35 & 1378 & It5. & & 6,3 & $11 M$ & 60 & & & 127 & & & 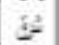 \\
\hline$\cdot$ & IH & 38 & 63 & 1812 & 138 & 2372 & 556 & 17.9 & 1035 & $12: 11$ & 73 & 14 & 21. & $=$ & y \\
\hline 8.2 & 124 & $5 n$ & 128 & 438 & 45 & 2401 & 369 & $17 \Omega$ & 1133 & [t] & 108 & 1595 & 7. & 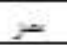 & 11 \\
\hline$\cdot$ & 1.6 & 455 & 97 & 34 & 35 & 3211 & 398 & 194 & 143 & $12 \cdot 6$ & 78 & 72 & 82 & ل & $\Rightarrow$ \\
\hline 43 & 49 & 5.75 & 152 & 4.55 & 5 & 186] & 320 & 17.56 & II & 15.3 & 115 & 1174 & 15. & $\Rightarrow$ & \\
\hline 35 & 41. & 31 & 3.] & 19.4 & 202 & & 3.5 & $18 \mathrm{R}$ & 134 & 134 & 1 & 301 & 38. & tz & \\
\hline$\cdot$ & 1 & 305 & 7 & II.71 & 123 & IB65. & 323 & 17.7 & DI. & 1289 & $M$ & 861 & 349 & $=1$ & نص \\
\hline 296 & 31 & 494 & 74 & {$[1106$} & 148 & 1137 & 453 & 19,02 & 136 & 1005 & 46 & 4992 & 65. & 20 & \\
\hline 189 & 31 & 358 & 53 & $\mathbb{I I} / 5$ & 12 & 283 & 406 & $\pi 99$ & 19. & 1255 & 92 & 2065 & 266 & . يرئ & \\
\hline
\end{tabular}

* تشير إلي أن قيمة هذا المحدد قبل الإنخفاض أحسن حالًا من نظيرة في المستوي القياسي المفترض؛ لذا لا داعي لتعديله.

المصدر: حسبت من الجدولين رقم (0) و (7) r- نزايد حدة الفقر في الوجه القبلي عن الوجه البحري، وفي الريف عن الحضر .

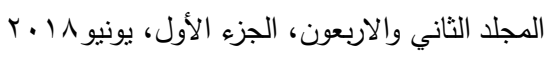


ع- مازالت محافظات صعيد مصر المستحوذة علي النسبة الأكبر من نسبة الفقر، ووصلت

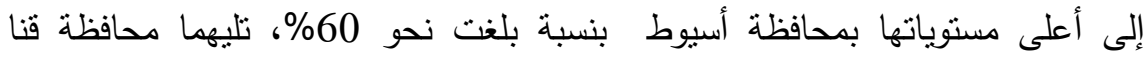

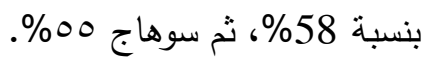

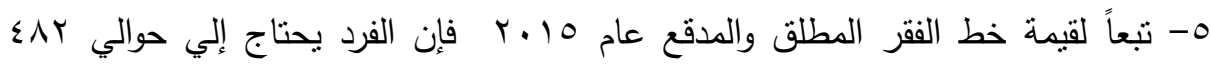

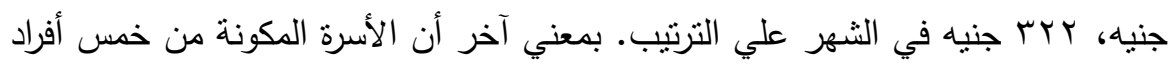

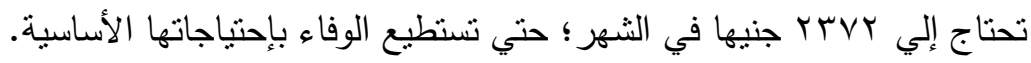

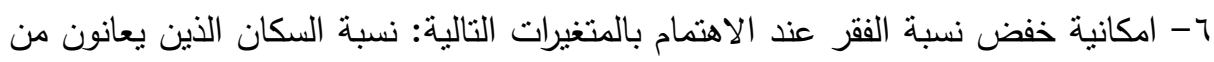
نقص التغذية، معدل البطالة، معدل التضخم، سكان المناطق الريفية، القيمة المضافة

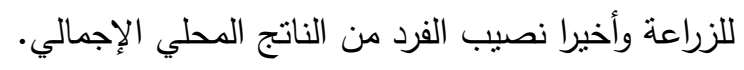

\section{اللجرصياهت}

1- التوسع في المشروعات متتاهية الصغر ، الصغيرة والمتوسطة وبصفة خاصة في القطاع

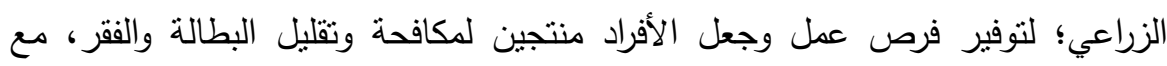
اعفاءها من الضرائب لحين الانتهاء من سداد القرض.

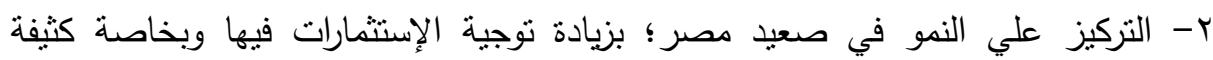

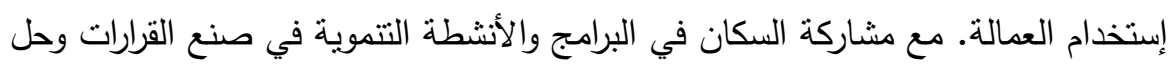

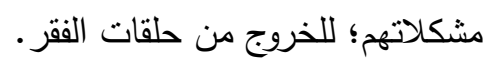
r- رفع الحد الأدني للأجور إلي من r r جنية للأسرة المكونة من ه أفراد؛ حتي يتسني لها الوفاء بإحتياجاتها الأساسية. ع- تحقيق الأمن الغذائي من خلال الحد من الفجوة الغذائية؛ وذلك بزيادة الإنتاجية الفدانية للمحاصيل الزراعية الغذائية، وإتباع التركيب المحصولي الأفضل الذبي يعظم صافي العائد 
0- تحقيق التوازن بين معدل النمو السكاني -للمناطق الريفية خاصة والسكان عامة- ومعدل

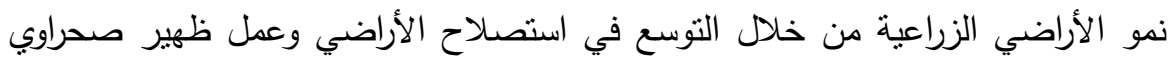

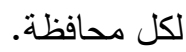

7- رفع القيمة المضافة للزراعة بإضافة منافع شكلية ومكانية وزمنية وخاصة التصنيع الزراعي، وعودة الدورة الزراعية وتفعيل دور المرشد الزراعي. والأهنمام بالتتمية الزراعية

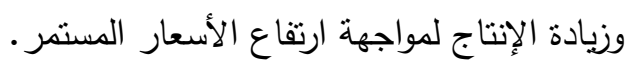

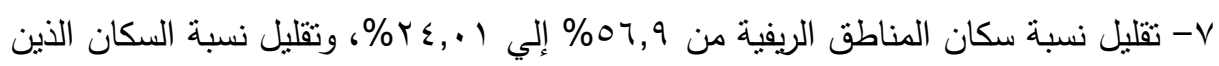

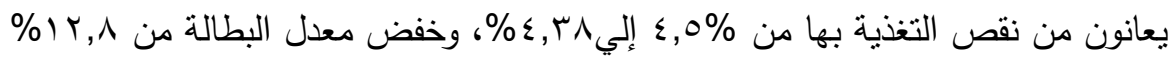

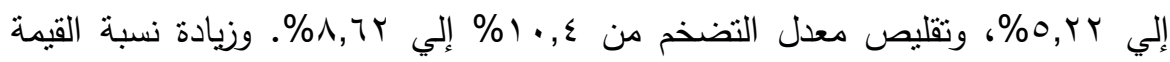

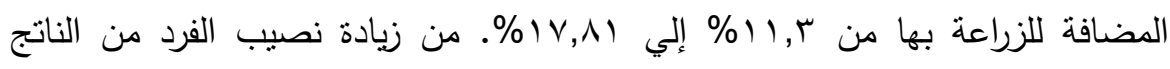

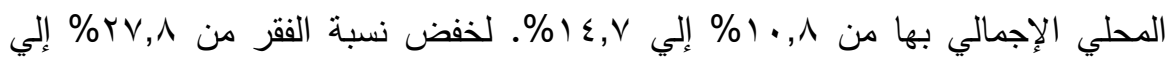
$\% 10,90$

\section{zall}

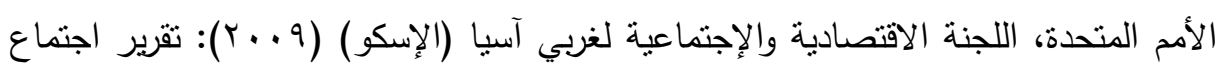

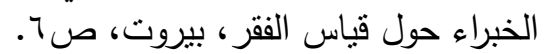

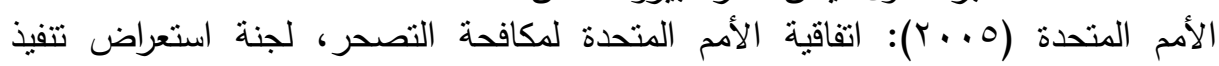

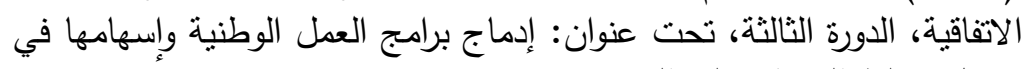

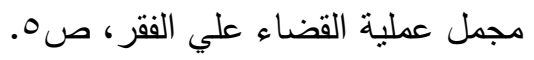

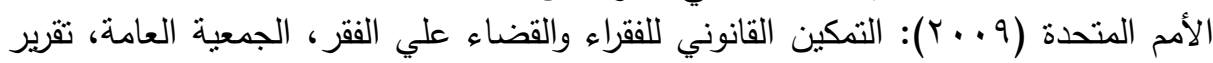

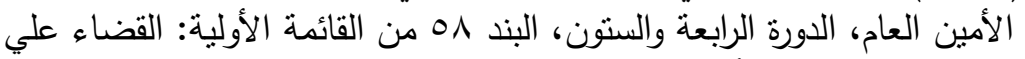

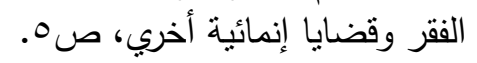

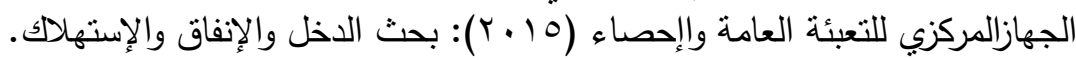

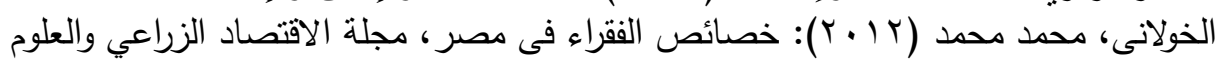

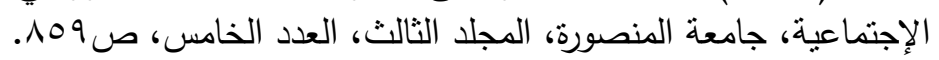

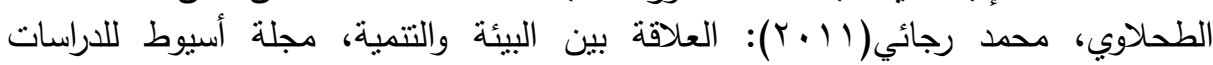

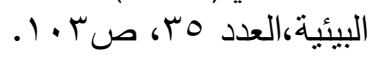

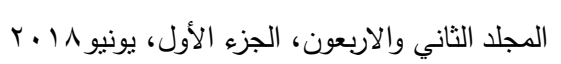


اللجنة الدائمة للتعاون الاقتصادي والتجاري لمنظمة التعاون الإسلامي (10 • ب): قياس الفقر

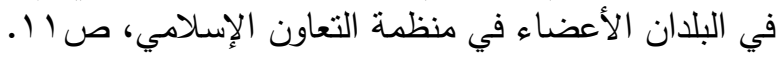

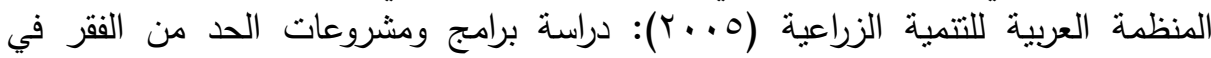

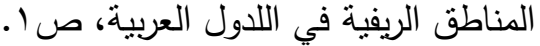

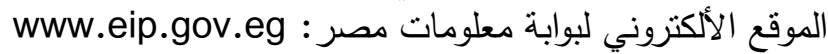

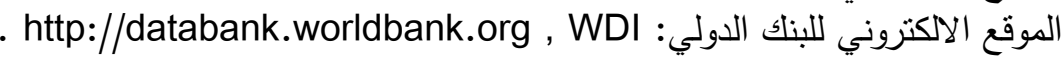

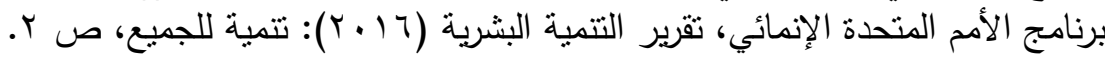

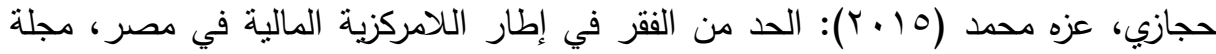

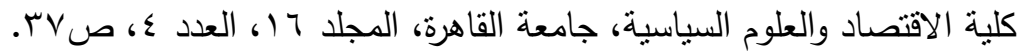

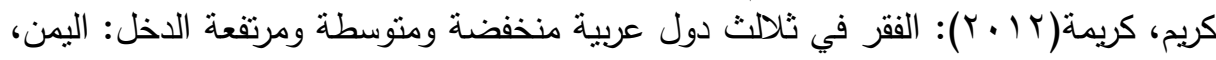

مصر، البحرين، مجلة عمران للعلوم الإجتماعية والإنسانية- المركز العربة العربي الإنية

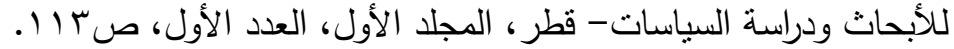

Amartya Sen (2005): Human Rights and Capabilities, Journal of Human Development,vol 6, no.2, p 152.

Blatagi, B., H., (2005): "Econometric Analysis of Panel Data", 3rd ed., John Wiley \& Sons, Ltd, West Sussex, pp 3-6.

Gujarati,D., N.,(2004), Basic Econometrhcs, 4th ed, chapter16, McGraw -Hill Higher Education, West Point, u k, pp 63768.

-Jameson Boex [et al.], (2006): Fighting Poverty Through Fiscal

Decentralization, USAID Report, p3.

Shyamsundar, Priya (2002): Poverty environment indicators, Environmental Economic Series, Paper No.4, The World bank Environment Department.

Ravillion, Martin (2000): On the Urbanization of Poverty, The World Bank, Washington, D.C. Processed.

World Bank,(2000): Entering the 21st century, World Development Report, pl5. 
محمد كامل إبراهيم ريحان وآخرون

\title{
THE PHENOMENON OF POVERTY IN EGYPT BETWEEN REALITY AND HOPED AND ITS POSITION AMONG SOME OF THE DEVELOPING COUNTRIES
}

Rihan, M. K. I. ${ }^{(1)}$; Elkassas, H. I. ${ }^{(2)}$; Abd El-Hamid, Seham, A. ${ }^{(2)}$ and Abd El-Fattah, Walaa, O. $^{(2)}$

1) Department of Agricultural Economics, Faculty of Agriculture, Ain Shams University 2) Department of Environmental Agricultural Sciences, Institute of Environmental Studies and Research, Ain Shams University.

\begin{abstract}
The issue of poverty, especially in third world countries is one of the biggest challenges facing the contemporary world, So this research aimed to identify poverty indicators in Egypt, and study the most important determinants of poverty, and in which they can reduce the levels of poverty in Egyptian society.

The study showed that the proportion of the poor in Egypt in 2015 represent about $27.8 \%$ of the total population, about $5.4 \%$ Living in extreme poverty. it appears increasing poverty in upper Egypt comparing with Lower Egypt, also Rural comparing with urban

we used Panel Data which depend on time series data,cross section data together.To overcome the problem of availability of data about the problem of poverty in particular, either through random sampling or time series. They both are incapable for current study requirements, time series has been selected for two years $(2014,2015)$, As the latest two availability by poverty data for the States studied reflection time dimension effect of sample time; It became a high degrees of freedom after $\mathrm{N}$ become high
\end{abstract}

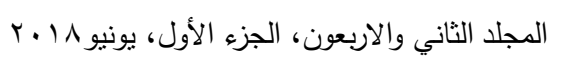


The study sample included 14 countries of some areas of various States, representing cross section data which appears Effect of sample regions. To see the determinants that affect on the ratio of poverty in Egypt and some developing countries included in the study.

As it turns through the standard estimate of poverty determinants that variables that biggest contribution in explaining the change in the level of poverty are: Prevalence of undernourishment (\% of population), Unemployment, total (\% of total labor force), Inflation, consumer prices (annual \%), Rural population (\% of total population), Agriculture, value added ( $\%$ of GDP), and GDP per capital.That 98\% of changes that occur in poverty due to these independent variables. decreasing the population undernourished by $1 \%$ consequent decreasing in the poverty rate by $1.01 \%$.

The study recommended reducing the proportion of rural population from $56.9 \%$ to $24.01 \%$, and reduce the proportion of undernourished people from $4.5 \%$ to $4.38 \%$, and reducing the unemployment rate from $12.8 \%$ to $5.22 \%$, and reducing the rate of inflation from $10.4 \%$ to $8.62 \%$, and increase the added value of agriculture from $11.3 \%$ to $17.81 \%$, and increase GDP per capita from $10.8 \%$ to $14.7 \%$. For reducing poverty from $27.8 \%$ to $15.95 \%$. this is achieved through attention to agricultural development and food security through the expansion of land reclamation, and increase productivity of agricultural crops; by collects fragmented holdings, and the return of the agricultural cycle, and activate the role of the agricultural guider. In addition to the establishment of small and micro projects

key words: Poverty, National Poverty, Extreme Poverty, Human Development, Determinants Of Poverty. 